\title{
The Sheet Metal Formability of AA-5083-O Sheets Processed by Friction Stir Processing
}

\author{
G. F. Miori, ${ }^{1}$ E. C. Bordinassi, ${ }^{1,2}$ S. Delijaicov, ${ }^{2}$ and G. F. Batalha ${ }^{3}$ \\ ${ }^{1}$ Instituto Mauá de Tecnologia, São Caetano do Sul, SP, Brazil \\ ${ }^{2}$ Centro Universitario da FEI, São Bernardo do Campo, SP, Brazil \\ ${ }^{3}$ Polytechnic School of Engineering, University of São Paulo, São Paulo, SP, Brazil
}

Correspondence should be addressed to G. F. Miori; gmioril@gmail.com

Received 12 April 2015; Revised 23 June 2015; Accepted 24 June 2015

Academic Editor: Amit Bandyopadhyay

Copyright (C) 2015 G. F. Miori et al. This is an open access article distributed under the Creative Commons Attribution License, which permits unrestricted use, distribution, and reproduction in any medium, provided the original work is properly cited.

\begin{abstract}
The aim of this study is to determine the sheet metal formability of AA-5083-O sheets processed by the Friction Stir Processing (FSP). The FSP process was studied and a FSP tool was built. Processing quality was verified by the metallography in the processing region, which established the voids presence. Tensile tests were carried out on FSP and non-FSP specimens, and the results showed that FSP specimens have 30\% greater resistance than non-FSP ones. The formability of FSP sheets was produced in MSC-MARC and Abaqus and these software products were compared by using the nonlinear FEM code. The Forming Limit Diagram was built with the results from both software products. A device to process FSP sheet metals was developed and the sheets were processed to validate the results from the software. The tools made for the bulge tests were circular and ellipse-shaped. After the bulge tests, the commercial sheets showed close approximation to those obtained from the software. The FSP sheets broke when inferior pressure was applied because of the defects in the FSP process. The results of the FSP presented the same formability of commercial sheets, however, with $30 \%$ greater strength.
\end{abstract}

\section{Introduction}

The Friction Stir Welding (FSW), patented in 1991 by the TWI Institute, is a method used to join two parts, defining a welding joint, with better mechanical properties than the original parts. Heat and friction are generated by the tool, which is inserted between the parts defining the plasticity condition. The tool is then removed from the parts and the regions welded are solidified and remain joined [1-3].

As the Friction Stir Processing (FSP) is an attractive way to refine grains, many studies on Superplasticity obtained from FSP joints were developed. The grain size obtained from a typical FSP joint is about 1 to $5 \mu \mathrm{m}$ and the extra fine grains range from 30 to $180 \mathrm{~nm}$. The grain size is a relevant factor to obtain superplastic materials [4].

Since FSP refines the grains, it is important to apply this process to the formability of complex sheets. It is not possible to obtain complex sheets by using the conventional process of formability and, to obtain a complex part, the number of parts is increased, as for the emergency door of the BAE 125/800 airplane. When formed under superplastic condition, the number of parts was reduced to 76 allowing the use of 1000 bolts [5-7].

The Forming Limit Diagram (FLD) is used to forecast the forming limit of a sheet. The forming limit is defined as the state in which localized thinning on the sheet starts during the forming, leading it to rupture. The forming limit is conventionally defined by a curve drawn in a graph, in which the major deformation is in the $x$-axis and the minor deformation is in the $y$-axis [8].

Practical tests are carried out to obtain the FLD diagram until the break occurs. These tests may be performed with the hydroforming, the bulge, or the Nakajima tests. After the tests, major and minor strains can be measured. Analytical models may be used to determine the FLD diagram and compare to the practical tests [9].

The bulge test consists in fixing a sheet blank into a circular or elliptical matrix and applying pressure with air 


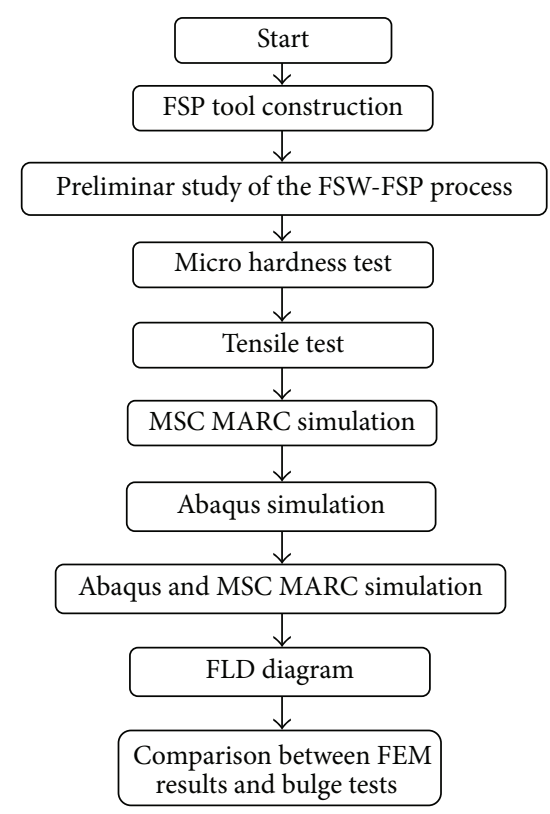

FIGURE 1: Schematic flowchart of the experimental procedure.

or oil to deform it. When the matrix is circular, the sheet is obtained after its deformation. For this test, the sheet has circle graduation and the dimensional variations are measured to determine the FLD points $[7,10]$.

Another way to study the formability of sheets is to form them at warm temperatures, as is the case of the AA-5083 aluminum alloy at $400^{\circ} \mathrm{C}$ [11]. The finite element method (FEM) is used to compare the practical results. To make the theoretical study by FEM, it is necessary to introduce many factors in the commercial package, such as the frictionless nature between the matrix and the sheet for the Nakajima test. Other important data to be considered for the FEM test are the mechanical properties of the material, obtained from uniaxial tests [12].

The commercial software Abaqus was employed to simulate Nakajima tests in warm conditions by using the finite element method. For this case, a MTS universal tensile testing machine was used and adapted with a furnace to carry out the Nakajima tests at high temperatures. The comparison between the real and theoretical tests was made with the analytical model developed with Abaqus. This FEM software has the ability to solve thermocoupled problems at high temperatures, which allows reducing the number of practical tests [11].

Lee et al. [12] studied the hot forming of the 6111-T4, 5083 $\mathrm{H} 18$, and 5083-O aluminum alloys for the conditions with and without FSP. A small region of the sheet was studied and Abaqus was used to validate the practical study. The FLD diagram was constructed and the warm formability of these materials was studied. The FSP region was concluded to have better formability than the material region.

Kim et al. [13] studied the formability of the 6111-T4 aluminum alloy using Abaqus to simulate the uniaxial test of the AA-6111-T4 with and without FSP. This formability study was carried out at room temperature and no significant differences between the FSP region and the material regions were found, since the FSP region showed the same formability properties as the AA-6111-T4 .

Leitão et al. [14] studied the formability of the AA-5182H111 and AA-6016-T4 aluminum alloys. For their study, the two aluminum alloys were processed by FSP but joined by dissimilar welding. Nakajima tests were conducted at room temperature and the results showed that the properties of the material and processed alloy are the same and are with good formability properties. The conventional welding process reduces the formability properties as FSP maintains good formability properties at room temperature.

\section{Experimental Procedure}

The objective of this study is to determine the formability of AA-5083-O sheets processed by FSP. The experimental procedure is illustrated in Figure 1.

2.1. Development of FSP Tool. The FSP tool was designed and constructed, consisting of a body, a shoulder, which transmits the heat generated by friction to the sheets, and a threaded pin to transport the material. The body was made of SAE 1045 steel to maintain the temperature constant during the process. The shoulder and pin were made of S2 tool steel. The pin diameter is $8 \mathrm{~mm}$ and the shoulder is $14 \mathrm{~mm}$. The length of the pin is $4 \mathrm{~mm}$. The ratio of 1.75 between the pin and shoulder diameters was determined by experimental procedure. Ratios greater than 2 were used for preliminary tests, but the pin broke. There is a groove at the shoulder back to prevent the material from escaping during the process. Figure 2 illustrates the FSP tool.

2.2. Characteristics of AA-5083-O. The AA-5083-O aluminum alloy used for this study is laminated alloy without 


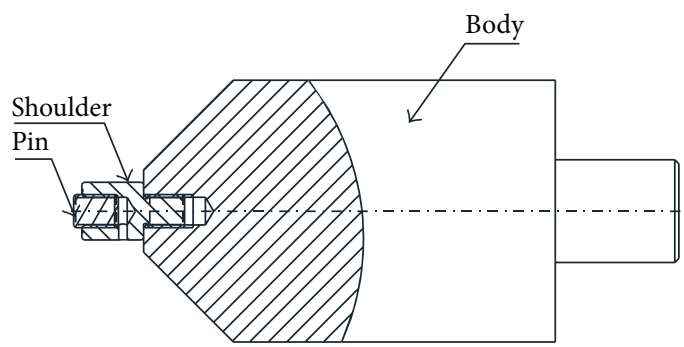

Figure 2: FSP tool.

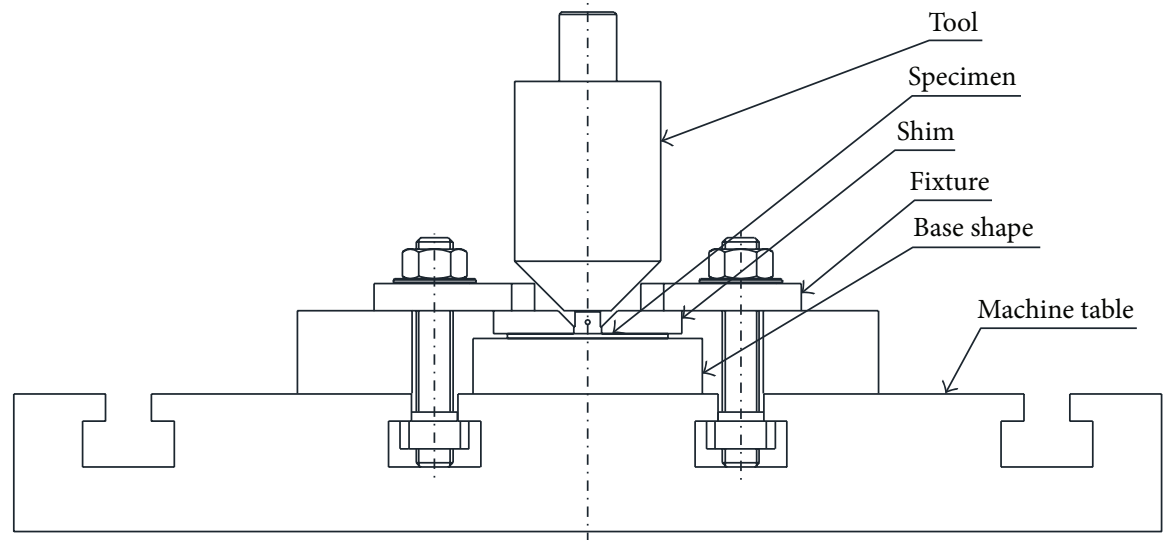

FIGURE 3: Fixture assemblies for the FSP tests.

TABLE 1: Chemical composition of AA-5083-O.

\begin{tabular}{lcccccccc}
\hline $\mathrm{Si}$ & $\mathrm{Fe}$ & $\mathrm{Cu}$ & $\mathrm{Mn}$ & $\mathrm{Mg}$ & $\mathrm{Cr}$ & $\mathrm{Zn}$ & $\mathrm{Ti}$ & $\mathrm{Bal}$ \\
$(\%)$ & $(\%)$ & $(\%)$ & $(\%)$ & $(\%)$ & $(\%)$ & $(\%)$ & $(\%)$ & $(\%)$ \\
\hline 0.9 & 0.16 & 0.02 & 0.65 & 4.6 & 0.06 & 0.03 & 0.06 & 0.15 \\
\hline
\end{tabular}

heat or hardness treatment. The sheets are commercial, $6.35 \mathrm{~mm}$ thick. Table 1 shows the chemical composition of 5083-O aluminum alloy.

2.3. FSP Specimens. The FSP specimens processing was carried out by a conventional milling machine. The sheet was supported by high-speed steel grinding shims and fixed by clamps at the upper part, leaving just enough space to pass the tool between the shims. Just one side of the sheet was processed in the preliminary tests. Figure 3 shows the assembly of the machine and Table 2 shows the preliminary conditions. A special camera (INSIZE model ISMPM2005) was used to characterize the defects. The best conditions are 1, 9, and 10 from Table 2 and were named CS1, CS2, and CS3, respectively. These conditions were selected because they were free of defects. Specimens were made following the E2448-08 standard in order to perform the uniaxial test. Two specimens were processed with and without FSP for each condition.
TABLE 2: Conditions to process preliminary specimens.

\begin{tabular}{lcc}
\hline Condition & $\begin{array}{c}\text { Rotational speed } \\
(\mathrm{rpm})\end{array}$ & $\begin{array}{c}\text { Longitudinal speed } \\
(\mathrm{mm} / \mathrm{min})\end{array}$ \\
\hline 1 & 500 & 65 \\
2 & 500 & 88 \\
3 & 500 & 104 \\
4 & 500 & 125 \\
5 & 400 & 65 \\
6 & 400 & 88 \\
7 & 400 & 104 \\
8 & 400 & 125 \\
9 & 328 & 65 \\
10 & 328 & 88 \\
11 & 328 & 104 \\
12 & 328 & 125 \\
\hline
\end{tabular}

Figure 4 illustrates the specimen for the tensile test. Many specimens were processed at the same time to reduce the amount of work. Figure 5 shows the layout of the specimen over the blank to be processed.

To process the specimen, it is necessary to process one side first and then the opposite side. A sequence was defined to avoid the tunnel defect, since during the process a small channel is left from the tool. First the raw side of the plate 


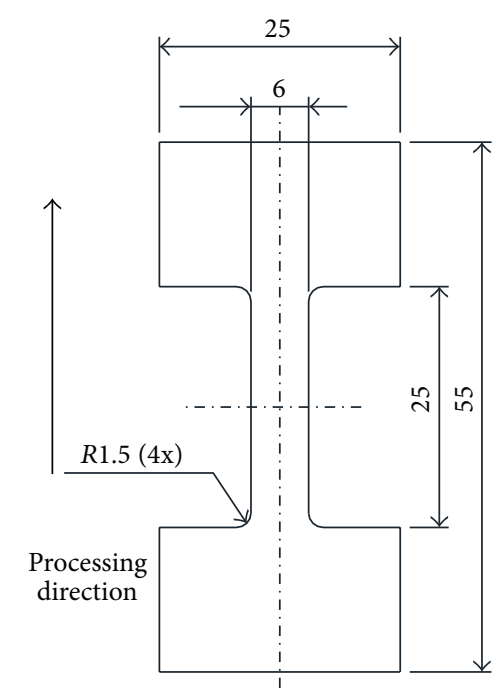

FIGURE 4: Specimen for the uniaxial test (mm).

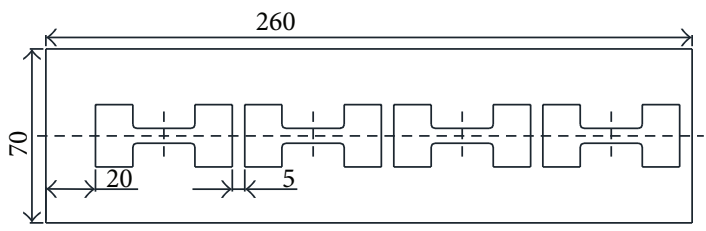

FIgURE 5: Nesting the specimens on the blank (mm).
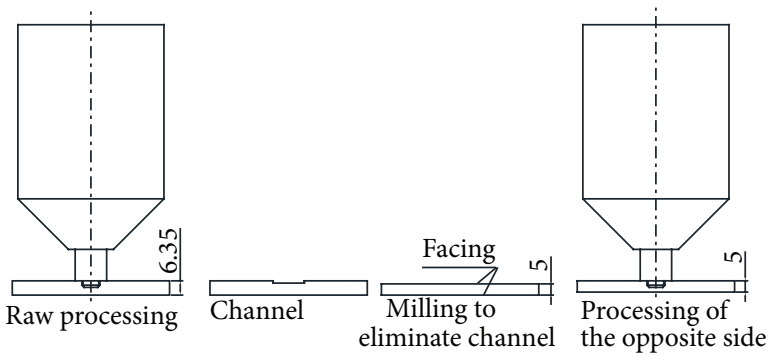

(a)

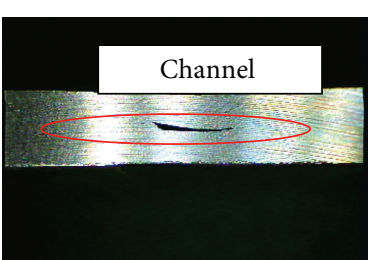

(b)

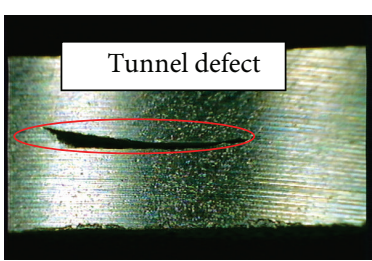

Figure 6: (a) Friction Stir Processing steps units (mm). (b) Tunnel defect after processing the opposite side.

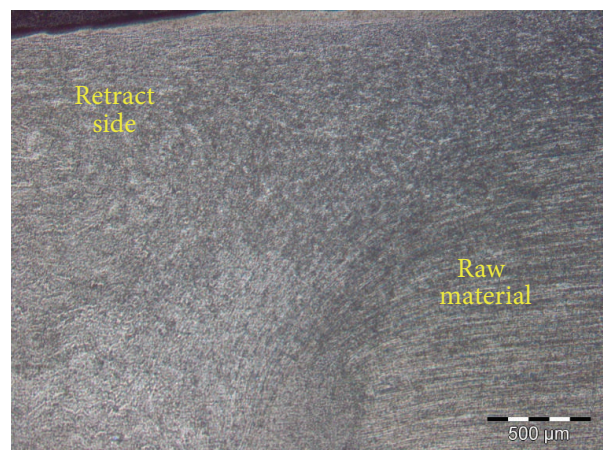

FIgURE 7: Metallography of FSP for CS1 condition. 


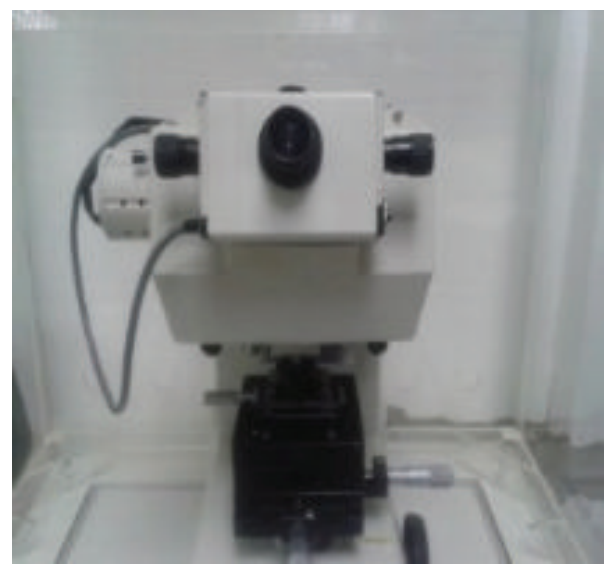

FIGURE 8: Hardness tester.

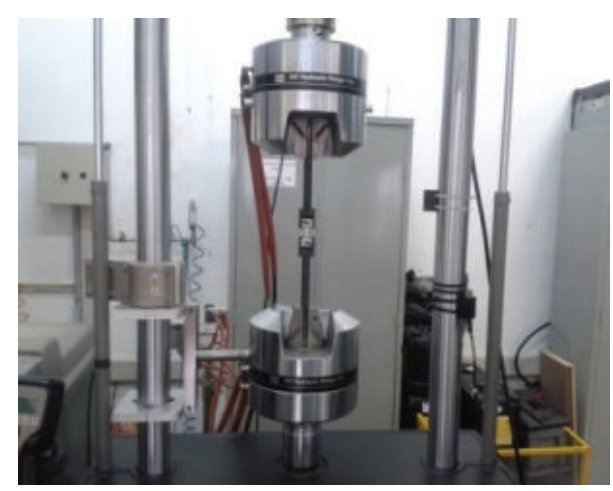

(a)

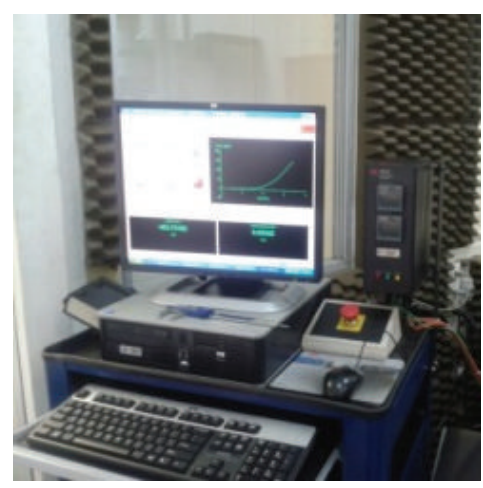

(b)

FIgure 9: (a) MTS tensile test machine. (b) Data acquisition system.
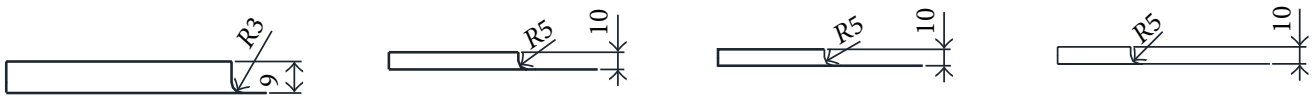

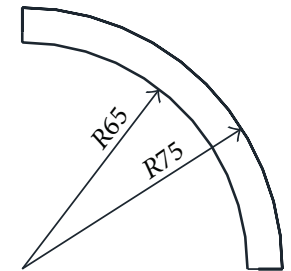

(a)

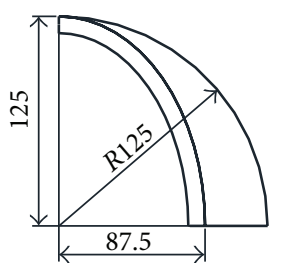

(b)

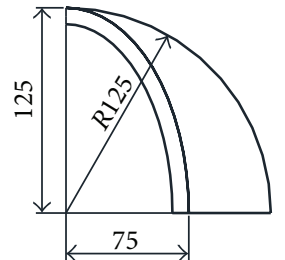

(c)

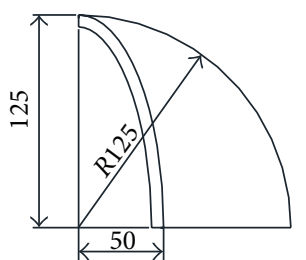

(d)

FIGURE 10: Blank holder used for the formability tests for MSC-MARC and Abaqus FEM commercial codes. (a) Circle. (b) $7: 10$ ellipse. (c) $6: 10$ ellipse. (d) $4: 10$ ellipse.

is processed. Then, because of the small channel, this side is milled before the opposite side is processed. This scheme is depicted in Figure 6.

Metallographic tests were performed with Keller attack. Figure 7 shows the raw material on the right side and the retraction side on the left side, showing the grain refinement after FSP for the CS1 condition.

\section{Microhardness and Uniaxial Tensile Tests}

Microhardness tests were performed for the CS1, CS2, and CS3 conditions. Two specimens without processing were studied for each condition; the specimens were embedded in Bakelite and sanded with 600-mesh granulation. The Shimadzu HMV2 microhardness tester was used with pyramidal 


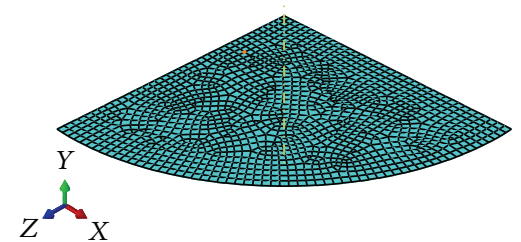

(a)

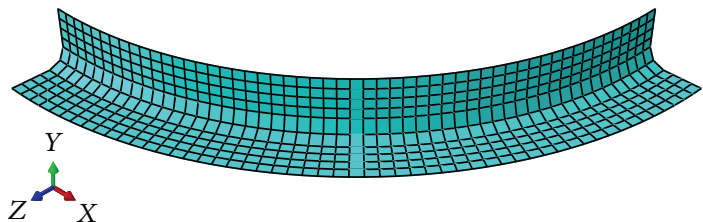

(b)

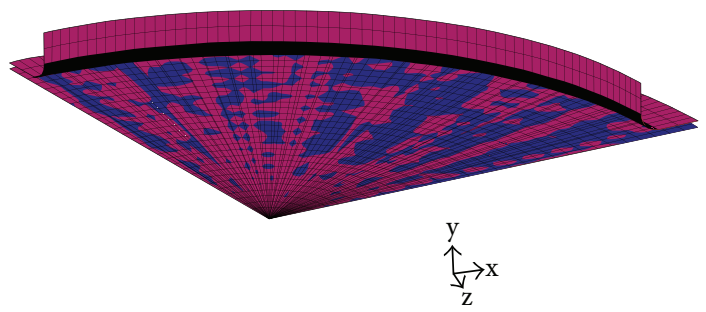

(c)

FIGURE 11: FEM element mesh. (a) Abaqus. (b) Discrete rigid finite elements at the clamp. (c) MSC-MARC.

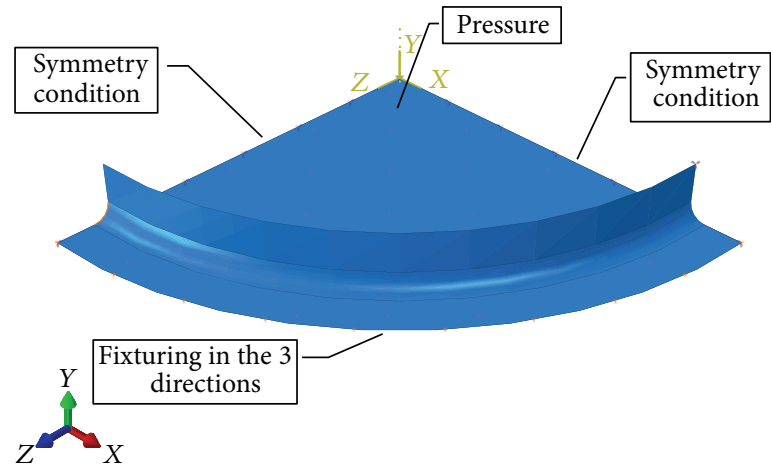

FIGURE 12: Boundary conditions of the models for MSC-MARC and Abaqus.

tip with a square base angle of $136^{\circ}$. An indentation series was made with $2 \mathrm{~mm}$ spacing. Figure 8 shows the microhardness tester. The uniaxial tests were performed in a MTS machine. The specimens were fixed with a special clamp and the machine software was used to measure the data of load and displacement. All the tests were carried out at the initial velocity of $4 \mathrm{~mm} / \mathrm{min}$ and, after the yield point, the velocity was changed to $2.54 \mathrm{~mm} / \mathrm{min}$. Figure 9 shows the assembly of the MTS machine.

3.1. Formability Tests. Two different approaches were used for the formability tests, bulge and Nakajima.

3.2. Bulge Tests. The bulge tests were carried out using 5 different surface sheets, with the CS1, CS2, and CS3 processing conditions. Figure 10 shows the clamp geometry for each formability test.

The thickness of the sheet for each test was $2 \mathrm{~mm}$. The finite element mesh used for MSC-MARC was the membrane element. For Abaqus, the membrane element was not used because of convergence difficulties. Figure 11 shows the finite element meshes for Abaqus and MARC. For MSC-MARC, the clamp is defined as a rigid surface; for Abaqus, a finite element mesh of rigid elements. The surface was not used for Abaqus since difficulties with convergence occurred.

Figure 12 shows the boundary conditions used in the models for the Abaqus and MSC-MARC studies. The sheet has symmetric conditions and the model represents its quarter. The fixation is applied to the border of the sheet.

The pressure applied under the sheet represents the load in the models. The pressure lasts 60 seconds with single values for each model. The stop criterion was according to the stress on the model, when the tensile strength of the material was reached. The average pressure was $14 \mathrm{MPa}$.

For both Abaqus and MSC-MARC, the stress strain curve was used for the CS1, CS2, and CS3 conditions. These data were obtained from the uniaxial tests. The material is considered elastic plastic and the stress strain curve is inserted as a table. In MSC-MARC, it is possible to plot the stress strain curve. Figure 13 shows the stress strain curve plotted in MSC-MARC for the CS1 condition.

The contact condition between the clamp and the sheet was established as rigid with a friction coefficient of 0.3 for 


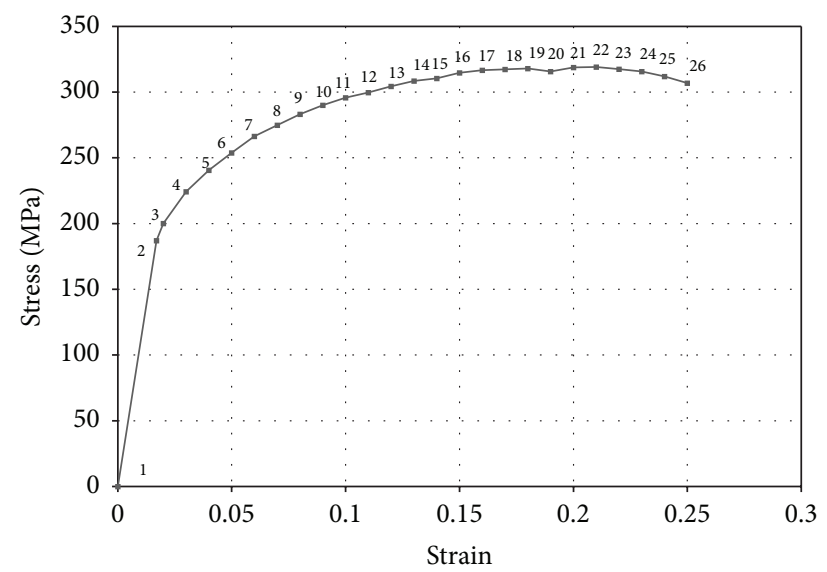

FIGURE 13: Stress strain curve plotted in MSC-MARC for condition 1.

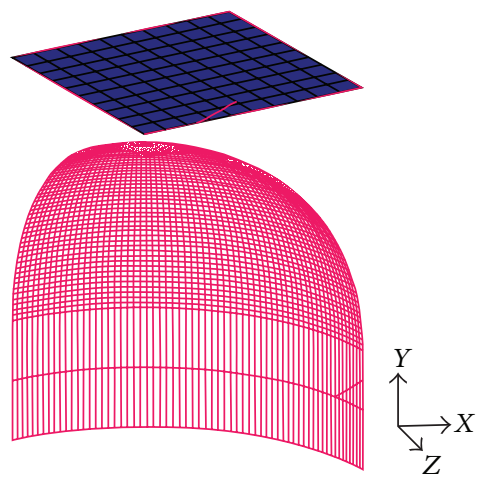

(a)

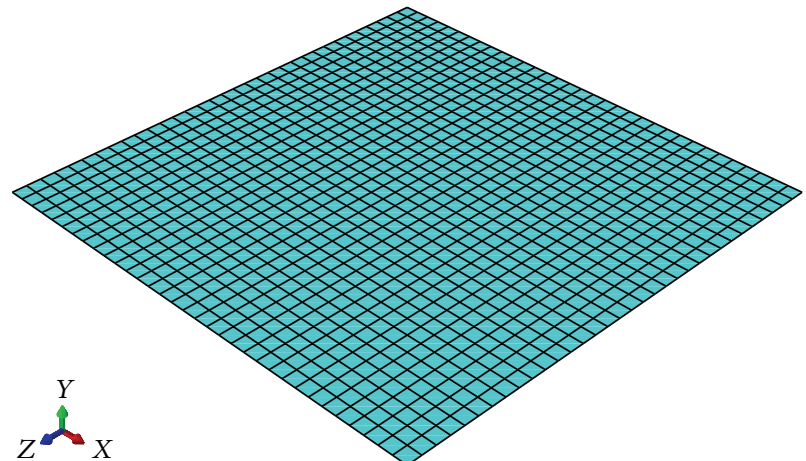

(b)

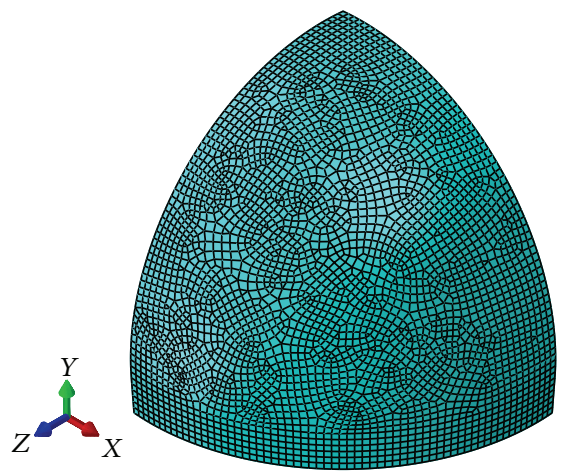

(c)

FIGURE 14: (a) Finite element mesh for punch and sheet in MSC-MARC. (b) Finite element mesh for the sheet in Abaqus. (c) Finite discrete rigid element mesh for the punch in Abaqus.

both software products. The simulation time was 60 seconds. The number of steps was for circular models 600 steps and for the ellipse models 1200 steps.

3.3. Nakajima Tests. The Nakajima test consists of forming sheets by using spherical punch, in which sheets with different sizes are formed. The sheets formed by Nakajima tests are $2 \mathrm{~mm}$ in thickness and are 100, 150, and $200 \mathrm{~mm}$ in size. The length of the sheet is constant at $200 \mathrm{~mm}$. As for the bulge tests, the membrane element is used in MSC-MARC and the shell element in Abaqus. Figure 14 shows the finite element mesh for both software products. The punch is treated as a surface in MARC and as a discrete rigid mesh in Abaqus.

Figure 15 illustrates the boundary conditions used for both software products. The sheet has symmetry conditions. The model shows the quarter of a sheet and the fix applied to the borders of the sheet in all directions. The punch has a vertical displacement condition for 60 seconds and moves $60 \mathrm{~mm}$ 


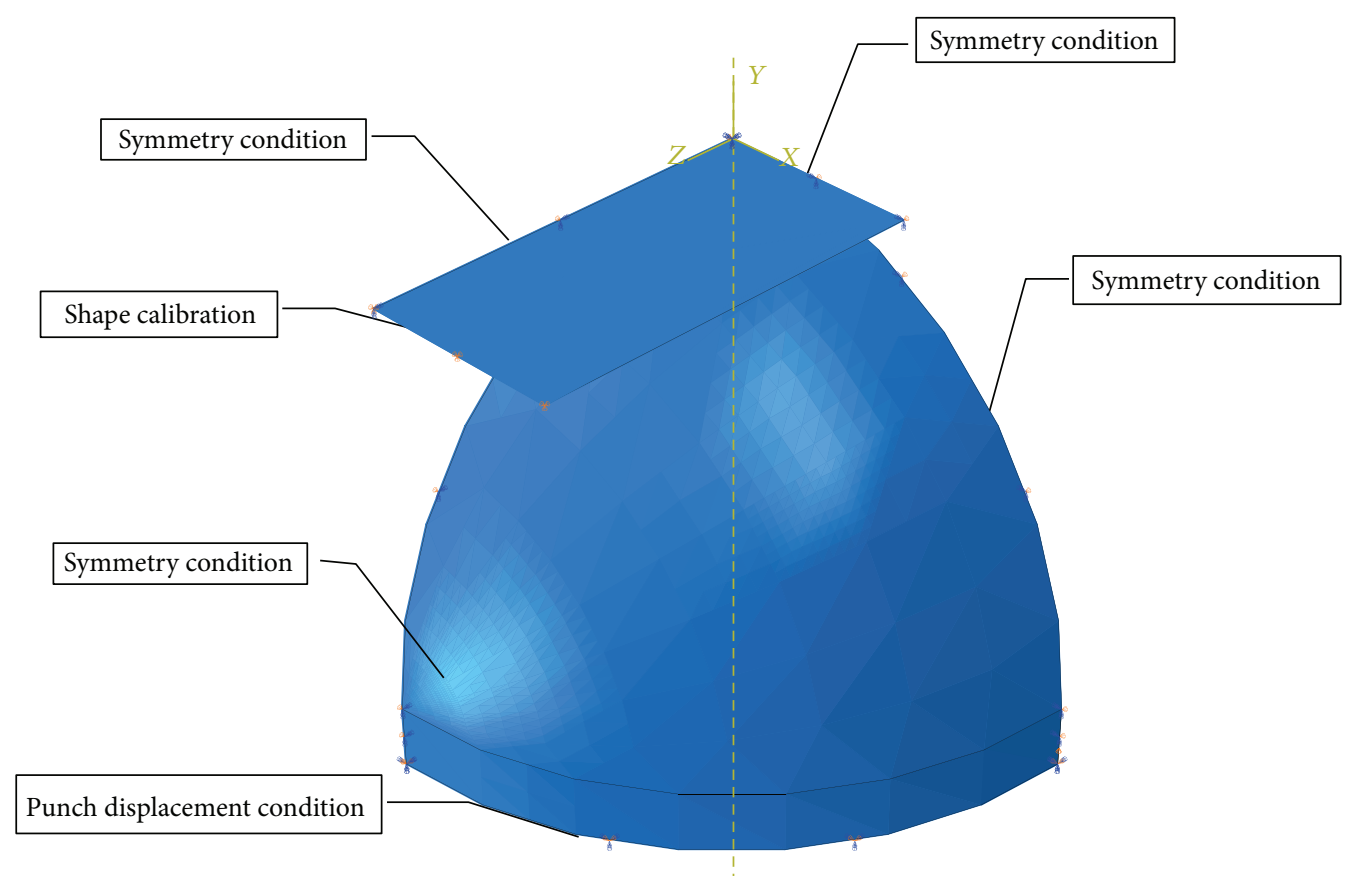

FIGURE 15: Boundary conditions for the Nakajima test.

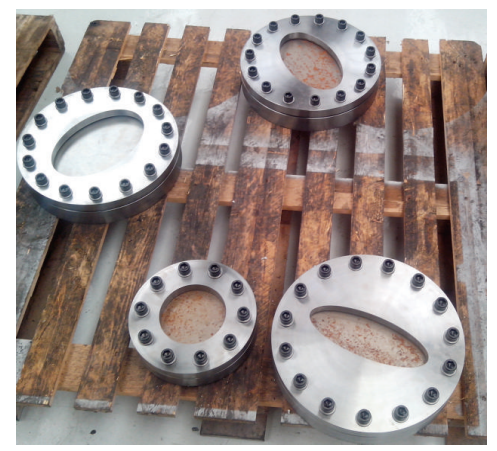

(a)

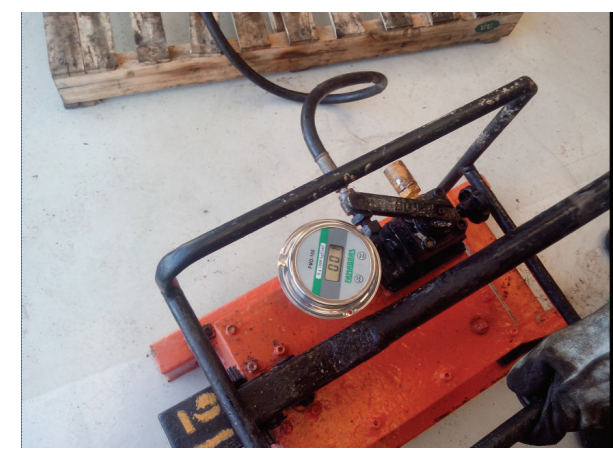

(b)

FIGURE 16: (a) Tools to validate the FEM analysis of the bulge tests. (b) Manual hydraulic pump developed by Rudloff Industrial.

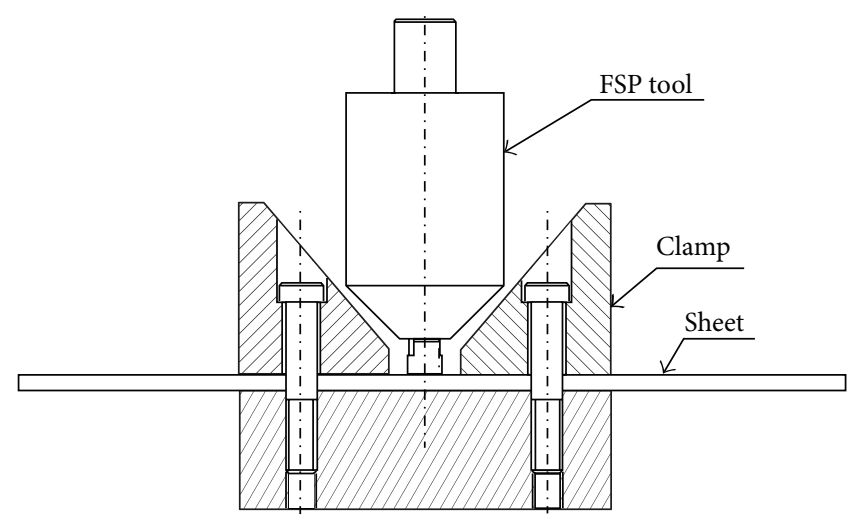

FIGURE 17: Device to process larger sheets. 

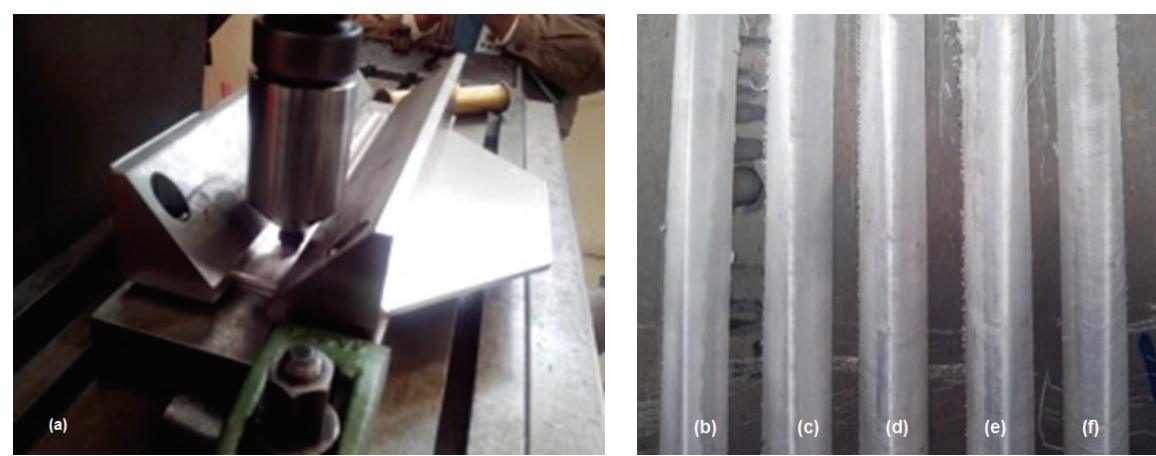

FIGURE 18: FSP of a large size sheet with a special device at $733 \mathrm{rpm}$; (a) special device in conventional milling, (b) $224 \mathrm{~mm} / \mathrm{min}$, (c) $168 \mathrm{~mm} / \mathrm{min}$, (d) $123 \mathrm{~mm} / \mathrm{min}$, (e) $88 \mathrm{~mm} / \mathrm{min}$, and (f) $65 \mathrm{~mm} / \mathrm{min}$.

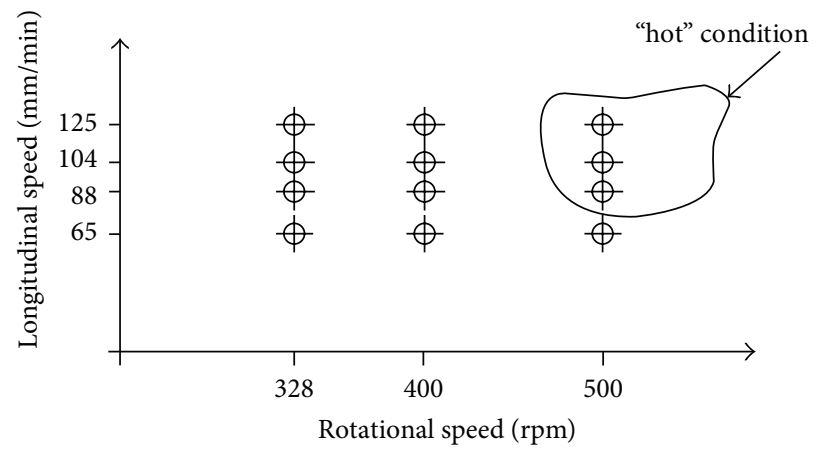

FIgURE 19: Processing conditions obtained with AA-5083-O.

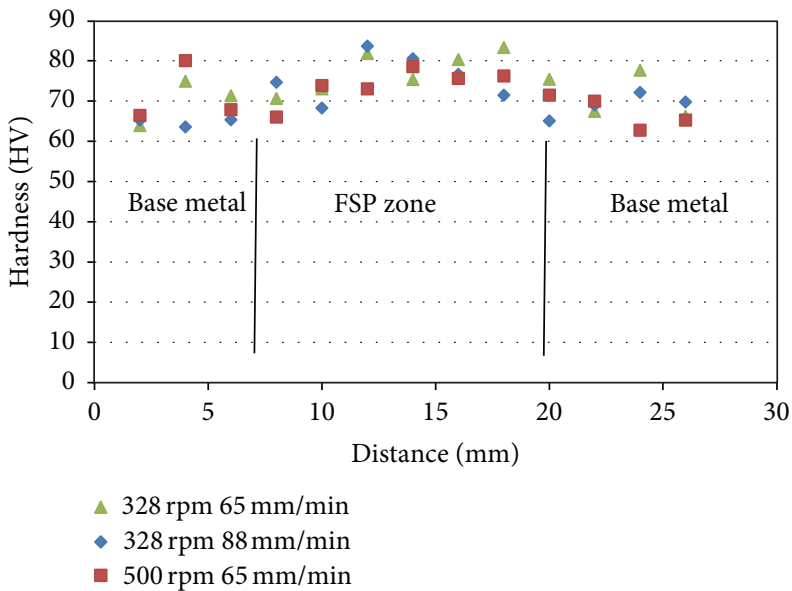

FIGURE 20: Microhardness test results for the FSP specimens.

vertically. For both software products, the contact condition between the surfaces of the sheet and punch was established as a rigid contact condition. The friction coefficient was 0.1 .

The simulation time for both software products is 60 seconds, and the number of steps was 1200 for all models.

\subsection{Bulge Tests Tools Development to Validate the FEM Anal-} ysis. Special tools were used for the bulge tests to validate the FEM analysis in four geometries with the same dimensions as in the FEM analysis. A high pressure manual pump developed by Rudloff Industrial was used to expand the sheets with hydraulic oil. The pump is provided with a digital manometer to control the pressure applied during the test. Figure 16 shows the tools made of SAE 1045 steel. A clamp between the sheet and the cover of tool was developed to avoid oil leakage during the tests.

3.5. Friction Stir Processing of Larger Sheets. The sheets used for the bulge tests have larger sizes and because of this the processing showed cold conditions; therefore, CS1, CS2, and 


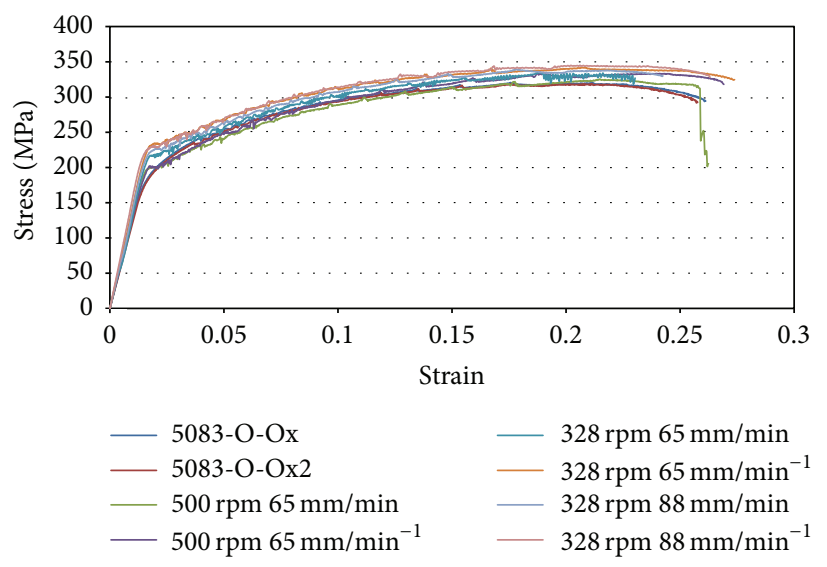

FIGURE 21: Stress strain curves for specimens with and without processing.

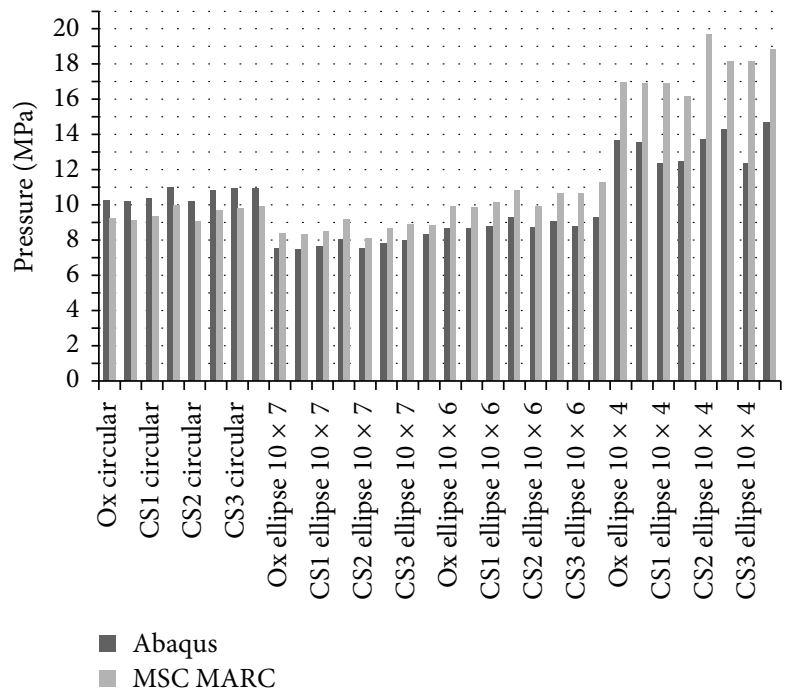

FIGURE 22: Applied pressure for the bulge tests using Abaqus and MSC-MARC.

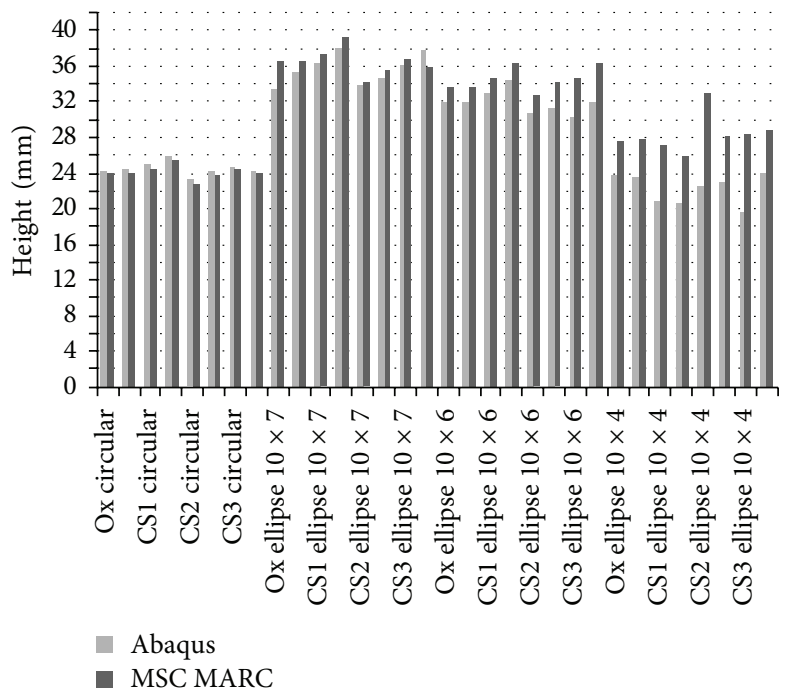

FIGURE 23: Maximum domes heights for the bulge tests using Abaqus and MSC-MARC. 


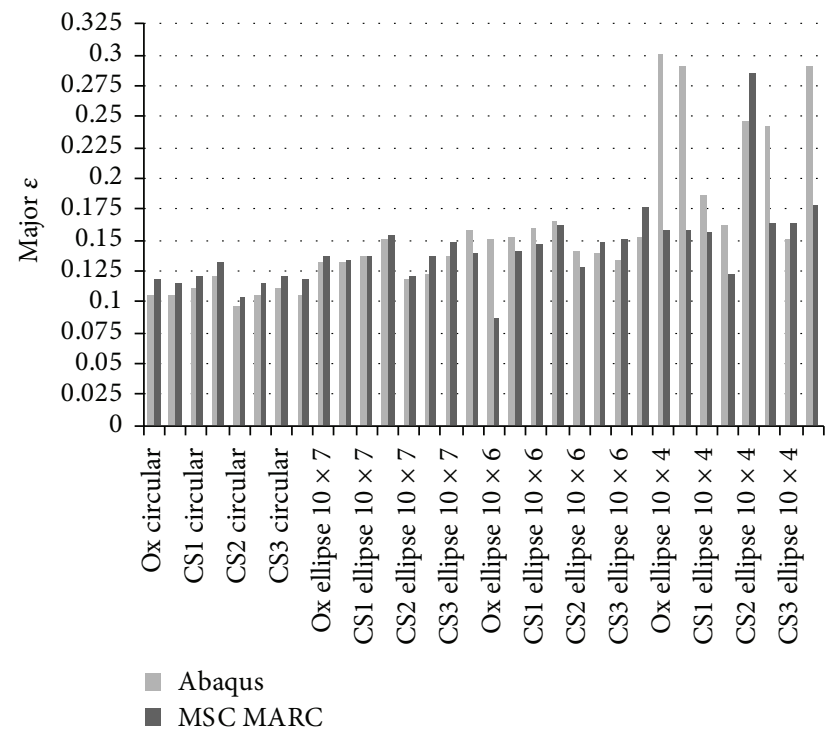

FIGURE 24: Maximum strain for the bulge tests using Abaqus and MSC-MARC.

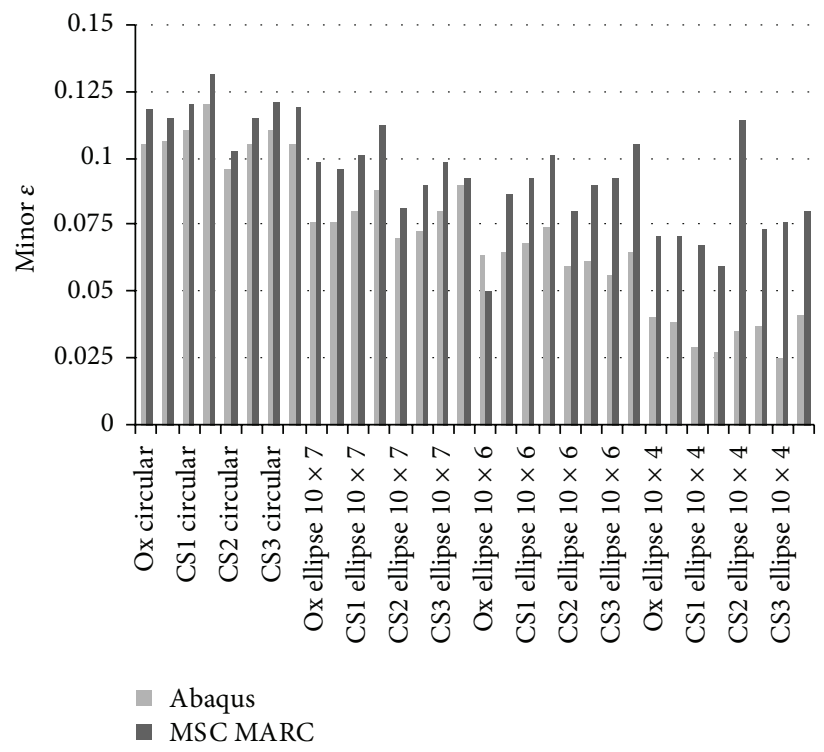

Figure 25: Minimum strain for the bulge tests using Abaqus and MSC-MARC.

CS3 did not work for these cases. New tests with higher rotation speed were carried out and the new condition was applied. The rotation speed was $733 \mathrm{rpm}$ and the longitudinal speed was $123 \mathrm{~mm} / \mathrm{min}$. A device to process the sheets was developed with a special characteristic that allows the sheet to move across. The distance between the tool and the bus machine is the limit to process one sheet. The step between the beads is $8 \mathrm{~mm}$, which is the same as the pin diameter. Figure 17 shows the device model and Figure 18, the surface of five FSP beads on a larger size sheet and the device assembled in conventional milling.

\section{Experimental Results}

4.1. Preliminary Processing Results. A macroscopic study of defects was carried out during the preliminary processing according to Table 2. A summary of the images obtained from this study can be seen at [5]. For such conditions, it was not possible to obtain processing because of "hot conditions." "Hot condition" occurs when the temperature during processing exceeds the melting temperature of the sheet and the material escapes between the shoulder and the sheet, which is confirmed by previous studies [15]. 


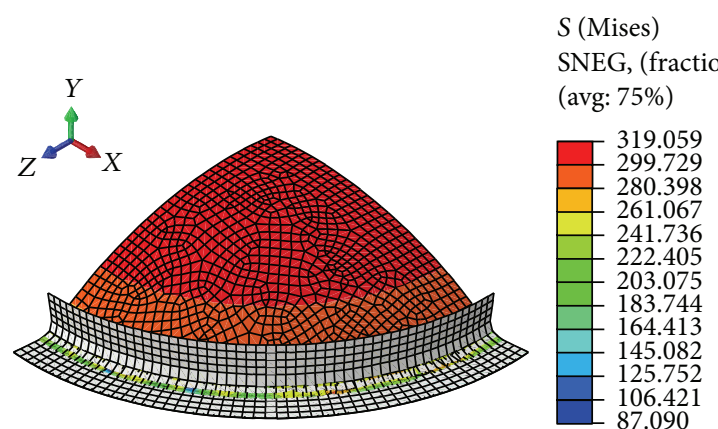

ODB: BULGEFRIOOXCRCULAR.odb

Abaqus/standard 6.10-1

Sun Jun 28 14:03:31 Hora oficial do Brasil 2015

Step: step- 1

Increment 28: step time $=40.03$

Primary Var: $S$ (Mises)

Deformed Var: $U$

Deformation scale factor: $+1.000 e+00$

(a)

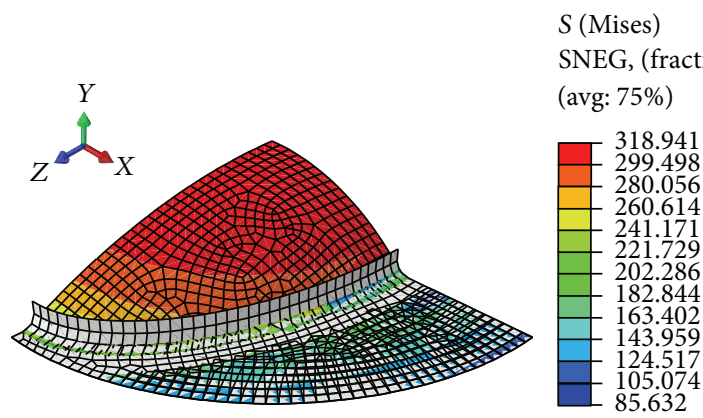

ODB: 5083OXELIPTICO106X250.odb

Abaqus/standard 6.10-1

Sun Jun 28 16:55:22 Hora oficial do Brasil 2015

Step: step-1

Increment 23: step time $=47.15$

Primary Var: $S$ (Mises)

Deformed Var: $U$

Deformation scale factor: $+1.000 e+00$

(c)

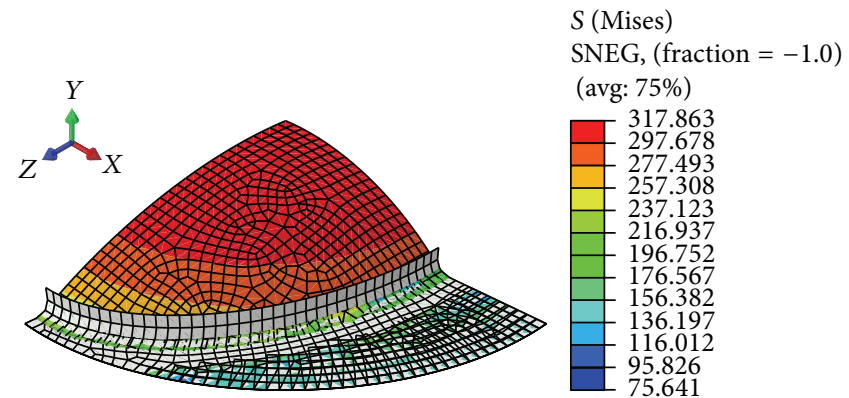

ODB: BULGE5083ELIPTICO107X250OX.odb Abaqus/standard 6.10-1

Sun Jun 28 16:46:19 Hora oficial do Brasil 2015

Step: step-1

Increment 29: step time $=40.35$

Primary Var: $S$ (Mises)

Deformed Var: $U$

Deformation scale factor: $+1.000 e+00$

(b)

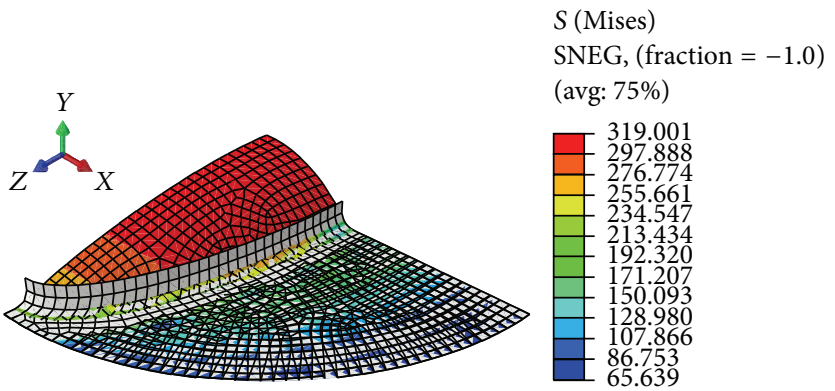

ODB: 5083OXELIPTICO104X250.odb

Abaqus/standard 6.10-1

Sun Jun 28 17:02:21 Hora oficial do Brasil 2015

Step: step-1

Increment 27: step time $=41.57$

Primary Var: $S$ (Mises)

Deformed Var: $U$

Deformation scale factor: $+1.000 e+00$

(d)

FIgure 26: Von Mises stress distribution for the CS1 condition in Abaqus. (a) Circular. (b) $10 \times 7$ ellipse. (c) $10 \times 6$ ellipse. (d) $10 \times 4$ ellipse.

It is then possible to find the ideal conditions for the process by looking at Figure 19, which indicates that conditions 3 and 4 of Table 2 are very "hot."

The microhardness tests showed an increase in the hardness for all FSP specimens. Figure 20 shows the microhardness values.

A series of uniaxial tests was carried out, in which two were without processing and six were with processing conditions. In the stress strain curve for each condition, yield strength was plotted and the tensile stress increased for the processing conditions.

Figure 21 shows the stress strain curves compared to the specimens without processing. FSP refines the grains and the yield and strength resistance increase. The numerical results for the curves of Figure 21 are shown in Table 3.
TABLE 3: Numerical results of uniaxial tests.

\begin{tabular}{lcccccc}
\hline Specimen & $\begin{array}{c}\sigma_{0.2 \%} \\
{[\mathrm{MPa}]}\end{array}$ & $\begin{array}{c}\sigma_{\max } \\
{[\mathrm{MPa}]}\end{array}$ & $\begin{array}{c}\varepsilon_{\text {uniform }} \\
{[\%]}\end{array}$ & $\begin{array}{c}\varepsilon_{\text {total }} \\
{[\%]}\end{array}$ & $\begin{array}{c}K \\
{[\mathrm{MPa}]}\end{array}$ & $n$ \\
\hline Ox & 190 & 320.57 & 21.06 & 26.12 & 528.05 & 0.18 \\
Ox1 & 191 & 319.07 & 21.1 & 25.77 & 527.95 & 0.19 \\
CS1 & 200 & 325.34 & 21.44 & 26.24 & 584.88 & 0.23 \\
CS1 & 203 & 334.02 & 18.7 & 26.92 & 609.23 & 0.24 \\
CS2 & 235 & 341.92 & 20.85 & 27.39 & 568.44 & 0.19 \\
CS3 & 225 & 339.23 & 17.74 & 24.24 & 616.22 & 0.23 \\
CS3 & 227 & 336.03 & 15.29 & 26.3 & 549.28 & 0.19 \\
\hline
\end{tabular}

Table 3 shows that processing specimens present hardening during the uniaxial test for the $500 \mathrm{rpm} \times 65 \mathrm{~mm} / \mathrm{min}$ 


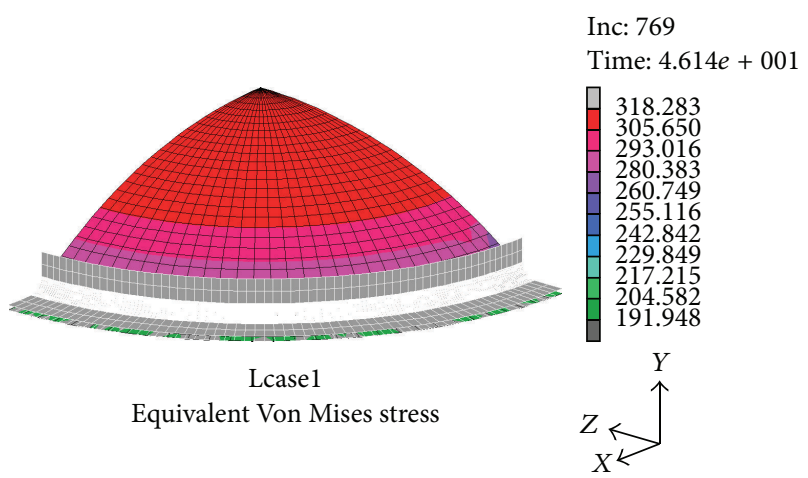

(a)

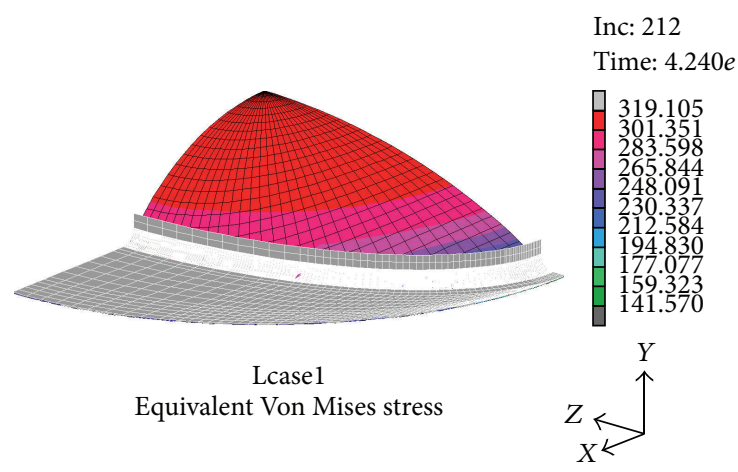

(c)

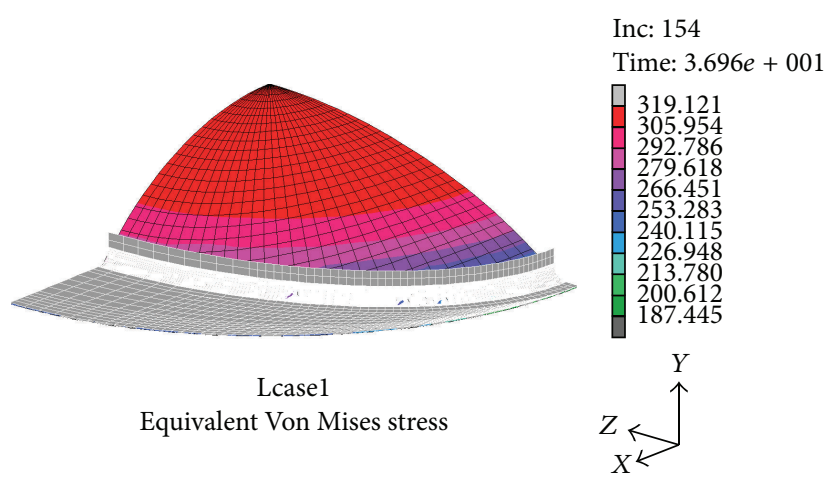

(b)

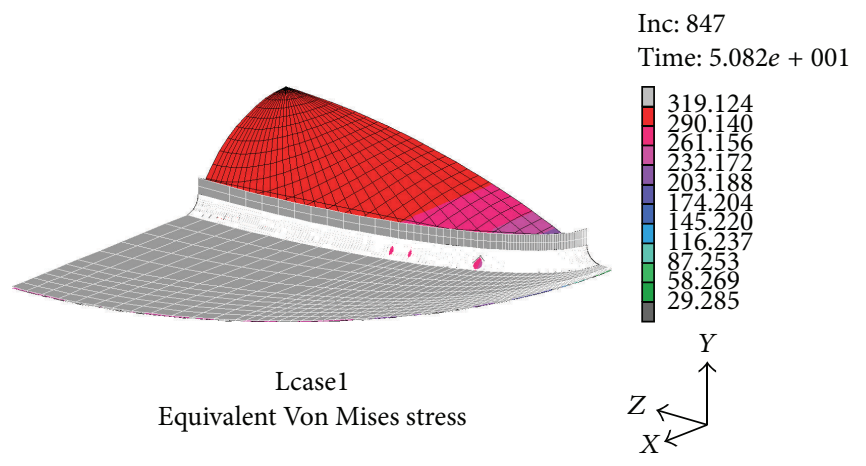

(d)

Figure 27: Von Mises stress distribution for the CS1 condition in MSC-MARC. (a) Circular. (b) $10 \times 7$ ellipse. (c) $10 \times 6$ ellipse. (d) $10 \times 4$ ellipse.

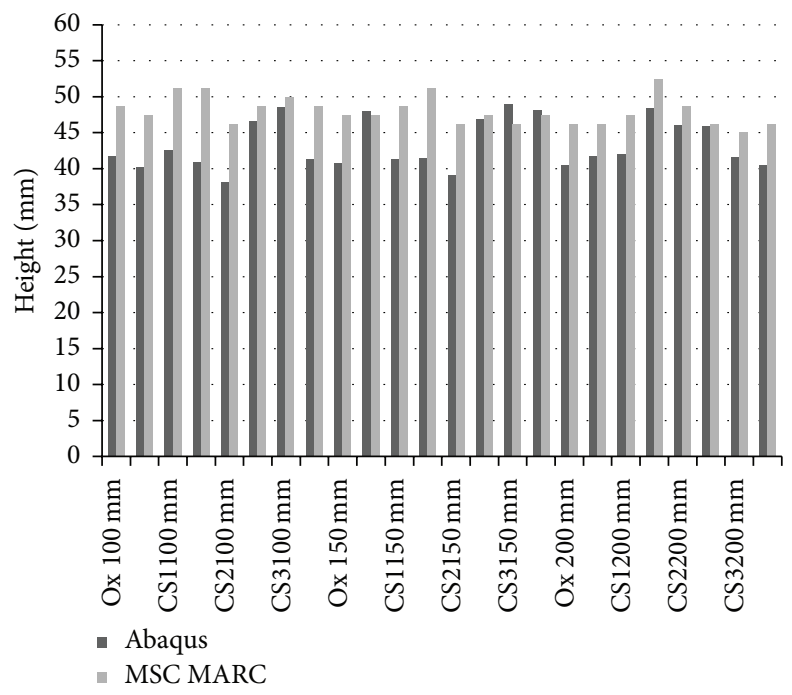

FIGURE 28: Maximum height for the Nakajima tests: comparison between MSC-MARC and Abaqus.

condition. When the "rotational speed versus longitudinal speed" relation is greater, the hardening is soft. On the other hand, the yield resistance increased by $19.4 \%$ for the $328 \mathrm{rpm}$ and $65 \mathrm{~mm} / \mathrm{min}$ condition.
4.2. Results from the Bulge and Nakajima Tests. The results from the bulge and Nakajima tests are summarized by the figures below. Each figure shows the comparisons between MSC-MARC and Abaqus. 


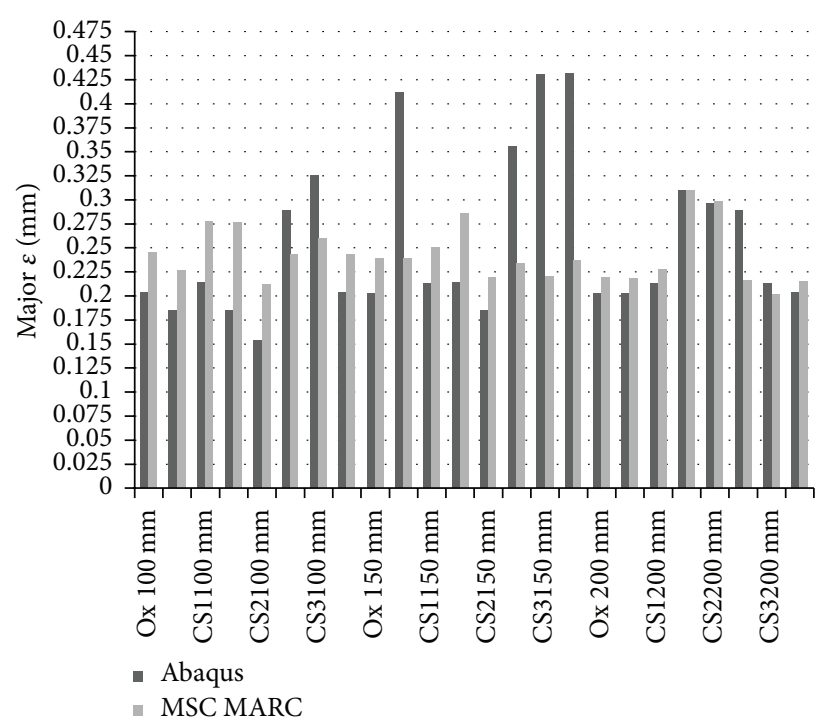

FIGURE 29: Major deformation for the Nakajima tests: comparison between MSC-MARC and Abaqus.

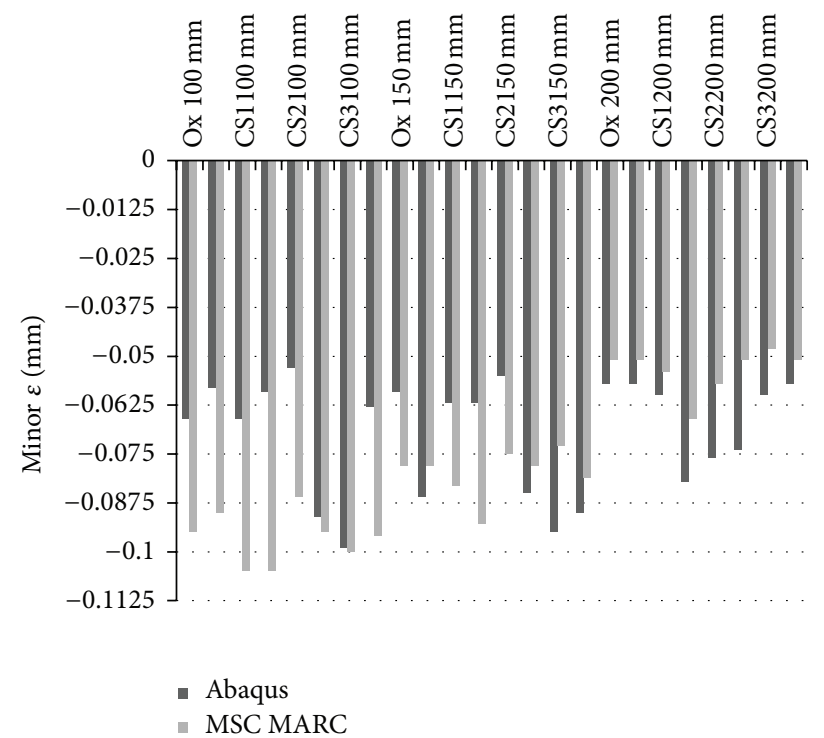

FIgURE 30: Minimum deformation for the Nakajima tests: comparison between MSC-MARC and Abaqus.

Figure 22 shows the average pressure applied for the bulge tests. The ellipse form shows higher values of pressure, and the major values are found using MSC-MARC. Abaqus presents higher values of pressure and the pressure applied is $14 \mathrm{MPa}$ for the $10 \times 4$ ellipse.

Figure 23 shows the maximum dome heights obtained in MSC-MARC and Abaqus for bulge tests with circular and elliptical forms. The results are similar for both, but MSCMARC shows higher values compared to Abaqus for the 10 $\times 4$ ellipse.

Figure 24 shows the maximum strain obtained in Abaqus and MSC-MARC for the conditions of maximum stress and maximum dome heights. The FSP process does not show differences in maximum strain. Sheets with FSP show better resistance with the same forming conditions. Discrepant values were obtained for $10 \times 4$ ellipse for both packages and the results are similar.

Figure 25 shows the minimum strain obtained with MSCMARC and Abaqus for the bulge tests. The behavior is similar to the maximum strains.

Figure 26 shows the Von Mises stress distribution for Abaqus and Figure 27 MSC-MARC of FEM analysis for the CS1 condition for the circular and elliptical forms. The simulation stops when the Von Mises stress reaches the maximum stress obtained from the tensile test.

Figure 28 shows the maximum height for the Nakajima tests for Abaqus and MSC-MARC. The values were obtained from the rupture condition. The behavior between the two software products is similar and the FSP process does not increase the maximum heights of the shapes. 


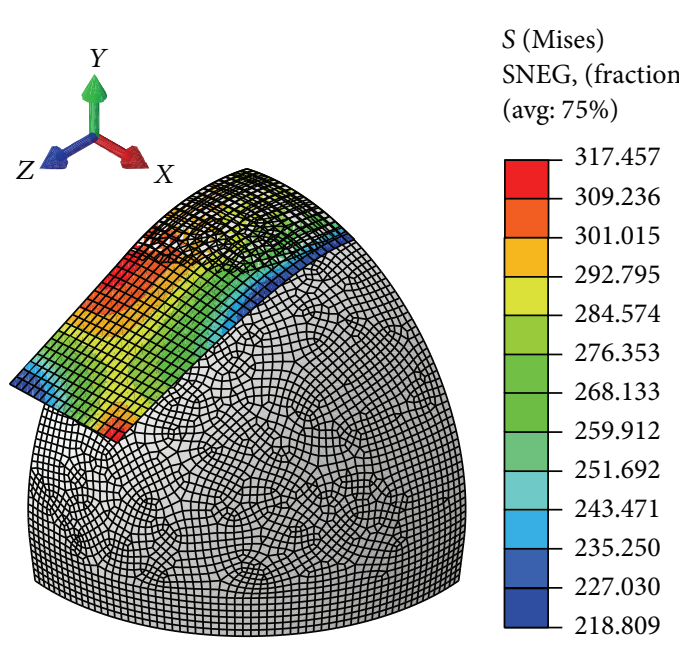

ODB: NAKAJIMA-5083OX50.odb

Abaqus/standard 6.10-1

Sun Jun 28 17:10:37 Hora oficial do Brasil 2015

Step: step-1

Increment 39: step time $=42.14$

Primary Var: $S$ (Mises)

Deformed Var: $U$

Deformation scale factor: $+1.000 e+00$

(a)

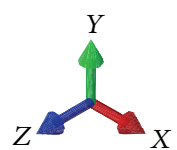

$S$ (Mises)

SNEG, $($ fraction $=-1.0)$

(avg: 75\%)

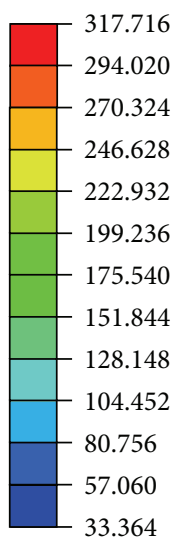

ODB: NAKAJIMAOX150.odb

Abaqus/standard 6.10-1

Sun Jun 28 17:20:44 Hora oficial do Brasil 2015

Step: step-1

Increment 38: step time $=41.13$

Primary Var: $S$ (Mises)

Deformed Var: $U$

Deformation scale factor: $+1.000 e+00$

(b)

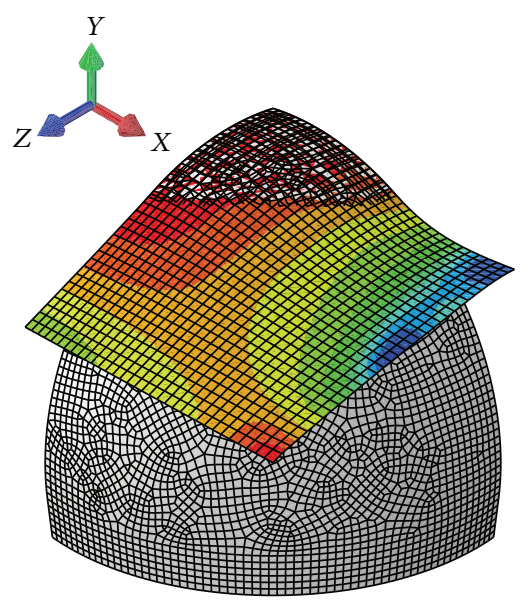

\section{$S$ (Mises)}

SNEG, $($ fraction $=-1.0)$

(avg: 75\%)

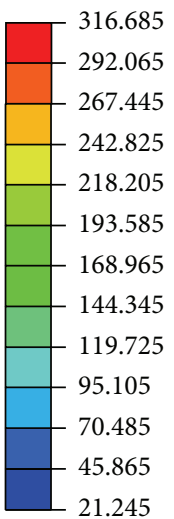

ODB: NAKAJIMA5083OX200.odb

Abaqus/standard 6.10-1

Sun Jun 28 17:27:37 Hora oficial do Brasil 2015

Step: step-1

Increment 29: step time $=40.24$

Primary Var: $S$ (Mises)

Deformed Var: $U$

Deformation scale factor: $+1.000 e+00$

(c)

Figure 31: Von Mises stress distribution in Abaqus for the Nakajima tests in CS1 condition: (a) $100 \mathrm{~mm}$, (b) $150 \mathrm{~mm}$, and (c) $200 \mathrm{~mm}$. 


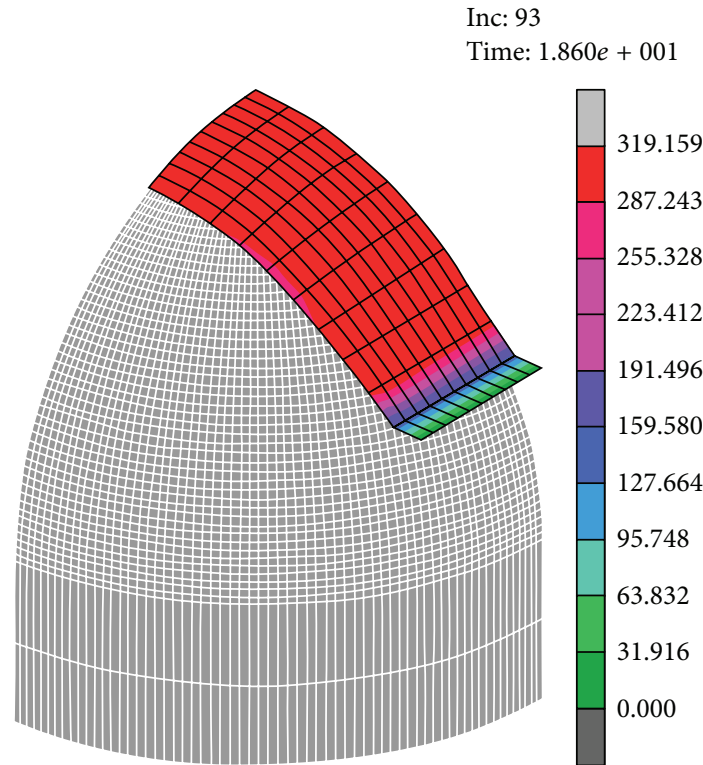

Teste Equivalent Von Mises stress

(a)

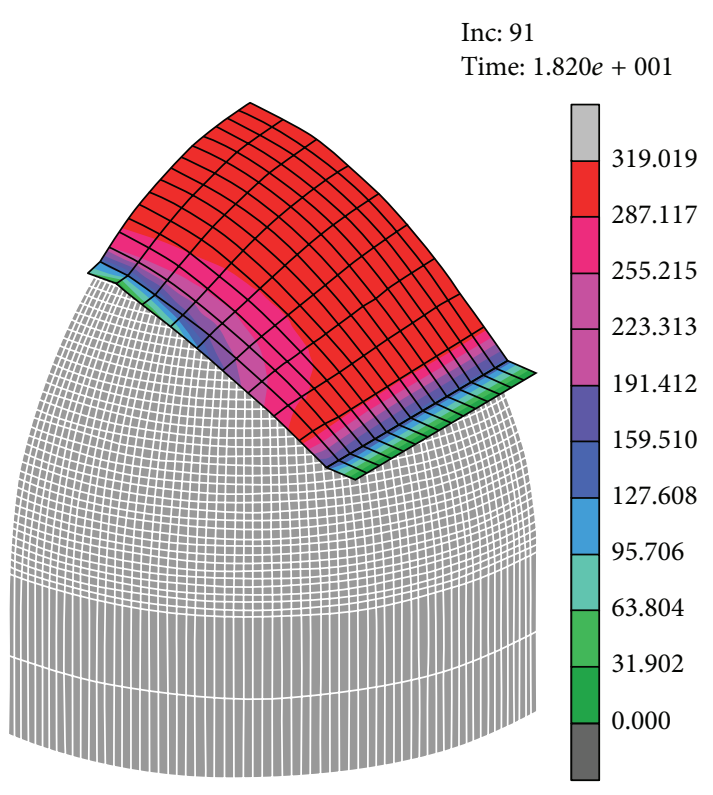

Teste Equivalent Von Mises stress

(b)

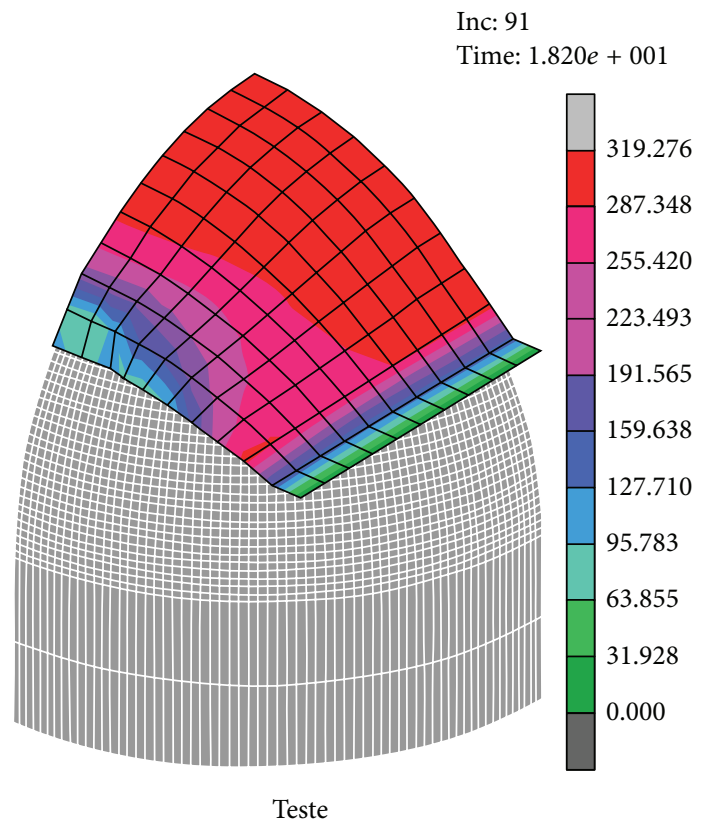

Equivalent Von Mises stress

(c)

Figure 32: Von Mises stress distribution in MSC-MARC for the Nakajima tests in CS1 condition: (a) $100 \mathrm{~mm}$, (b) $150 \mathrm{~mm}$, and (c) $200 \mathrm{~mm}$.

Figures 29 and 30 show the maximum and minimum strains and compare MSC-MARC to Abaqus. Discrepant values are found but the results show that the formability does not increase with the FSP process. The values obtained in Abaqus and MSC-MARC are similar.

Figure 31 shows the Von Mises stress FEM results for Abaqus and Figure 32 shows the Von Mises stress FEM results for MSC-MARC for the Nakajima tests. The stop condition in the analysis of CS1 is the maximum. Von Mises stress reaches the maximum stress obtained from the tensile test.

The Forming Limit Diagram is determined with the results from the FEM analysis. The right side is composed of the bulge tests and the left side is composed of Nakajima tests. Figure 33 shows the FLD diagram obtained in MSCMARC and Figure 34, the FLD diagram obtained in Abaqus. The FSP processing does not increase the forming of sheets 


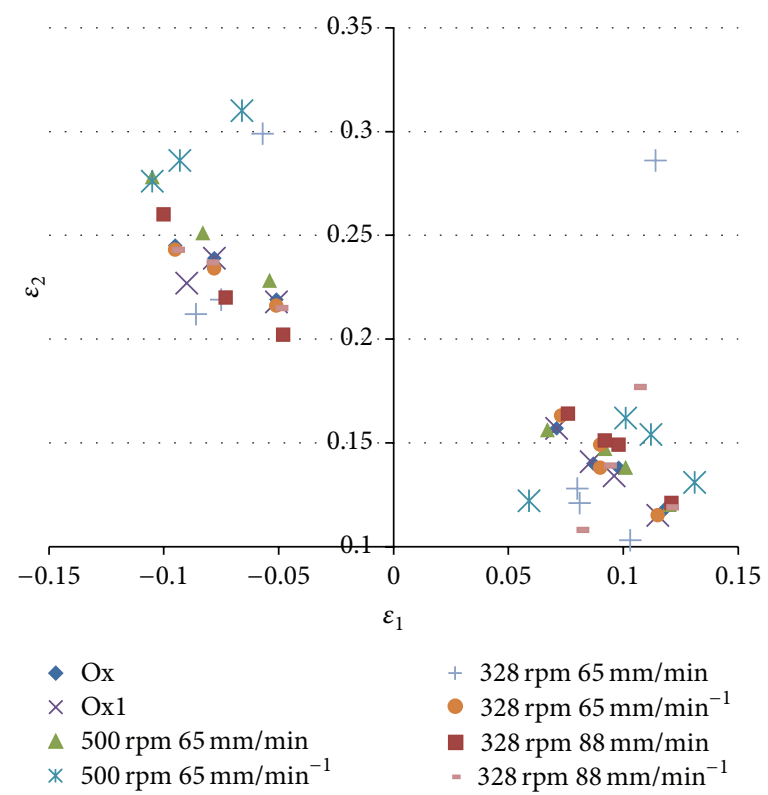

Figure 33: FLD diagram results for MSC-MARC.

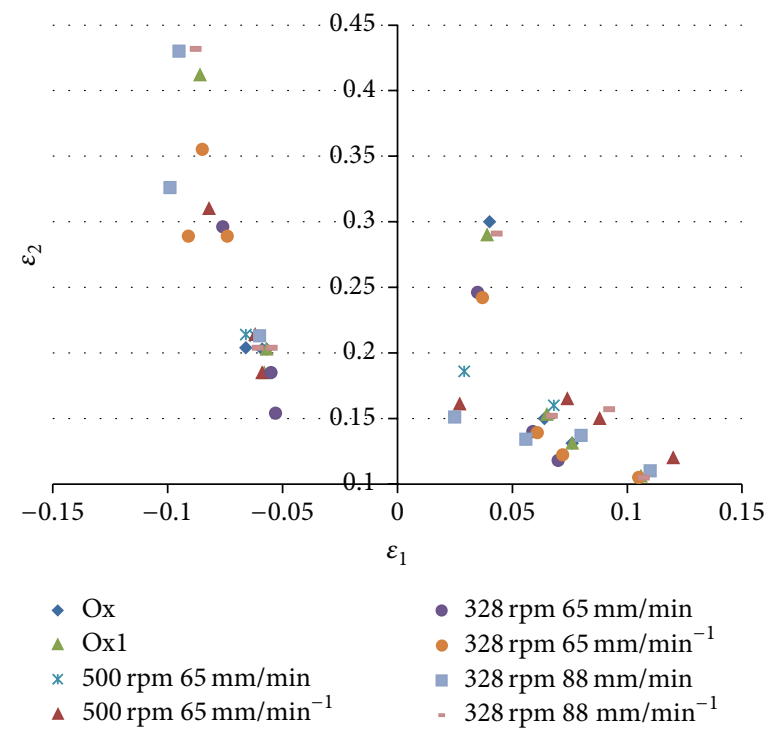

FIGURE 34: FLD diagram results for Abaqus.

processed; however; FSP sheets have higher resistance. The FEA by Abaqus shows major strains on the right side of the FLD diagram compared to MSC-MARC.

4.3. Validation of the Bulge Tests. A series of sheets was processed by FSP for the CS4 condition to validate the tests. Figure 35 shows the sheets after FSP before machining the thickness of the sheet to remove the ribbon flashes left from the process. To reduce the processing time, only the deformed area of the sheet was processed.

The wear of the tool was evaluated and no wear was observed after $25150 \mathrm{~mm}$ of processing. Figure 36 shows the wear evolution on the tool at each sheet processed.
SEM images were made in CAM SCAN 3200 LN Microscope. Figure 37 shows the tool after $25150 \mathrm{~mm}$ of processing, in which the aluminum is seen to have adhered to the tool (B) and a crack (A), which did not change the FSP condition, since it is possible that it appeared at the first contact with the part, once the crack region is at the start of the thread.

The friction region $(\mathrm{C})$ is indicated on the tool and is coated with aluminium but there is no significant wear on the tool after FSP.

Table 4 shows the comparison between the height of the domes and the strains for MSC-MARC and Abaqus in the sheets without processing. The results were very close to the practical tests. 


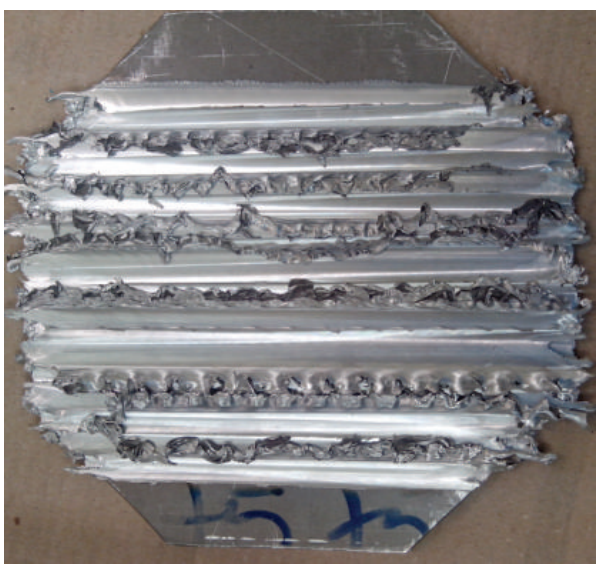

(a)

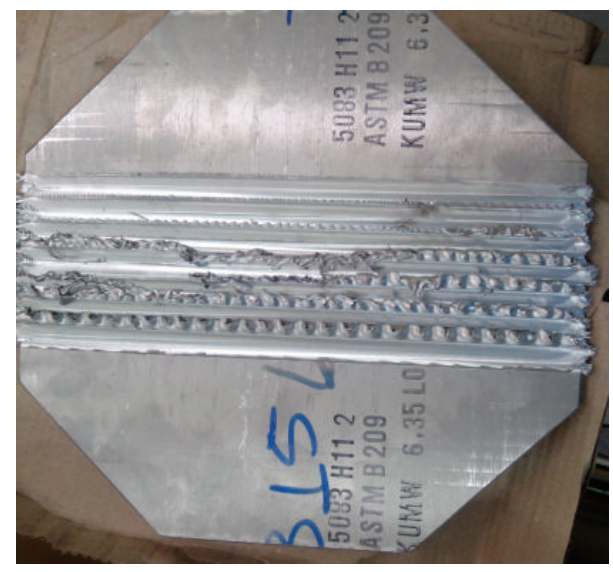

(b)

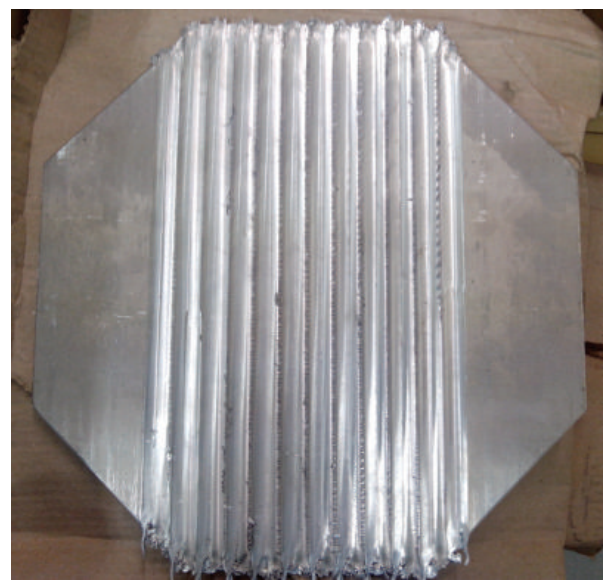

(c)

FIgURE 35: AA-5083 sheets processed for the bulge tests. (a) Circular tool. (b) $10 \times 4$ ellipse. (c) $10 \times 7$ ellipse.

TABlE 4: Comparison between the height of the domes and the strains in MSC-MARC and Abaqus in the sheets without processing.

\begin{tabular}{lcccc}
\hline Specimen & $\begin{array}{c}\text { Pressure } \\
(\mathrm{MPa})\end{array}$ & $\begin{array}{c}\text { Height } \\
(\mathrm{mm})\end{array}$ & $\varepsilon_{\text {major }}$ & $\varepsilon_{\text {minor }}$ \\
\hline Ox circular, MARC & 9.228 & 24.117 & 0.118 & 0.118 \\
Ox circular, Abaqus & 10.233 & 24.235 & 0.105 & 0.105 \\
Ox circular, experimental & 9.228 & 19.4 & 0.055 & 0.055 \\
Ox MARC, 10 $\times 7$ ellipse & 8.4 & 36.642 & 0.113 & 0.082 \\
Ox Abaqus, 10 $\times 7$ ellipse & 7.5 & 33.364 & 0.131 & 0.076 \\
Ox experimental, 10 $\times 7$ ellipse & 8.4 & 34 & 0.105 & 0.065 \\
\hline
\end{tabular}

The maximum strains occurred at the top of the sheet which is confirmed by the theoretical and software results. Figure 38 shows the maximum strain distribution in the nonprocessed $10 \times 7$ ellipse sheet compared to MSC-MARC results. Circles were drawn on the sheet to measure the deformation.

The practical tests with processed sheets result in disruption before reaching the maximum pressure predicted by the software. This occurred because of the defects in the sheets caused by the lateral displacement of the tool. As the lateral displacement is $8 \mathrm{~mm}$ and the shoulder is $14 \mathrm{~mm}$ in diameter, a channel is formed in each pass, and when the next pass occurs, the material fills this void leaving a tunnel defect in each pass.

Figure 39 shows a crack in the elliptical and circular sheets after processing. In the elliptical sheets, the crack occurred at the intersection between the tool radius and the base. In the circular sheets, the crack occurred at the top.

\section{Conclusions}

For this study, a FSP tool was developed with AA-5083-O aluminum alloy, so as to define suitable conditions to establish a friction stir process window: $500 \mathrm{rpm}$ and $65 \mathrm{~mm} / \mathrm{min}$, $328 \mathrm{rpm}$ and $88 \mathrm{~mm} / \mathrm{min}$, and $328 \mathrm{rpm}$ and $65 \mathrm{~mm} / \mathrm{min}$. A series of uniaxial tests was carried out with friction stir processed specimens compared to those nonfriction stir processed. Their respective stress strain curves were obtained.

Nakajima and bulge tests were simulated using Abaqus and MSC-MARC commercial FEM software to determine the formability of the AA-5083-O aluminum alloy processed and nonprocessed by FSP. Their results were compared to those of the software. 


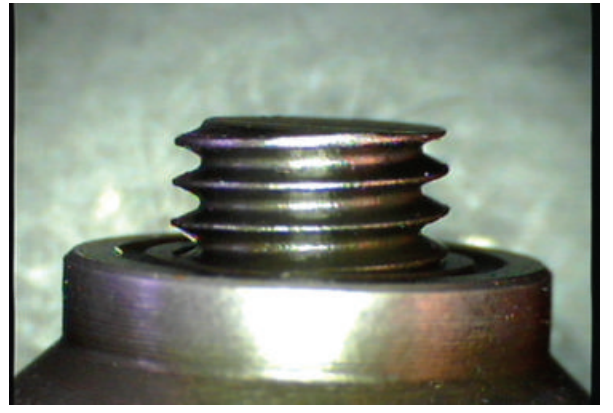

(a)

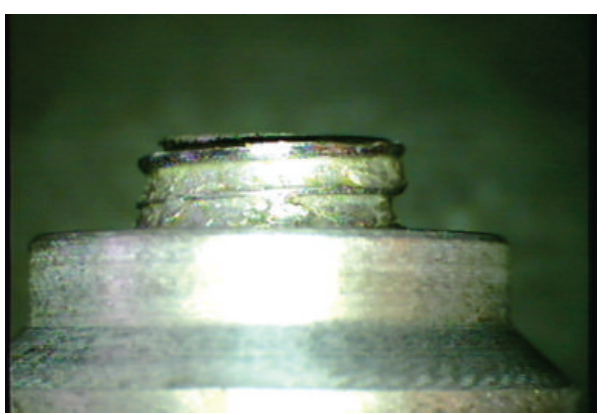

(c)

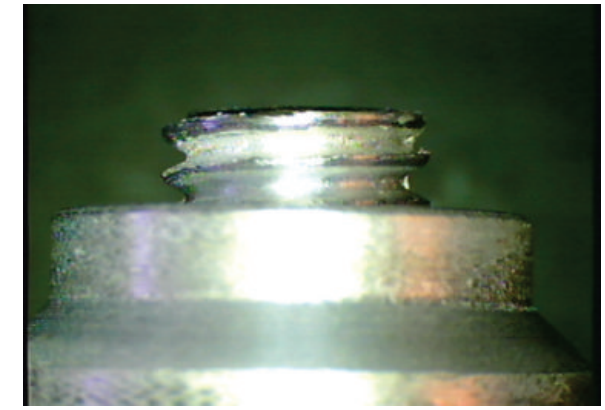

(b)

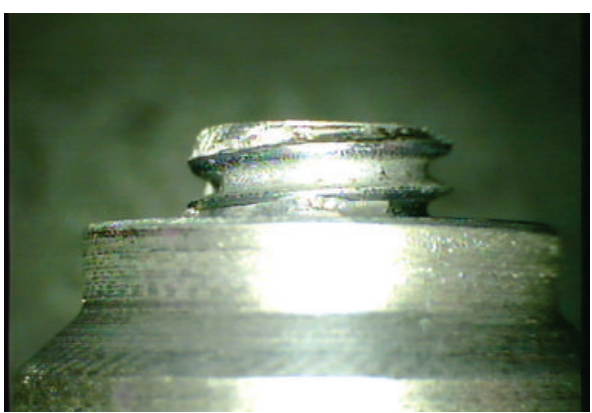

(d)

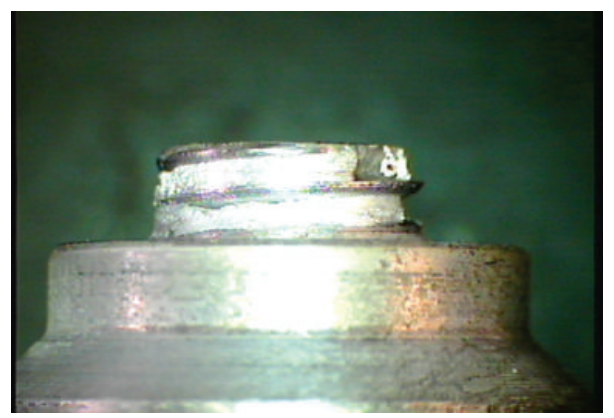

(e)

FIgURE 36: Wear of the tool pin after processing the sheets: (a) new tool, (b) $7550 \mathrm{~mm}$, (c) $11710 \mathrm{~mm}$, (d) $19070 \mathrm{~mm}$, and (e) $25150 \mathrm{~mm}$.

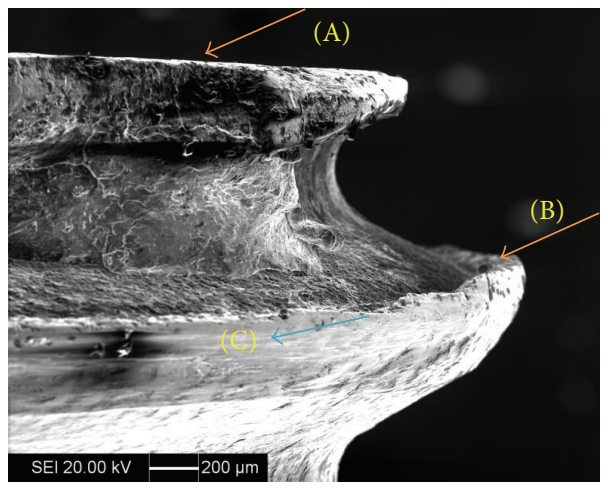

FIGURE 37: SEM image of the FSP tool after $25150 \mathrm{~mm}$ of processing: (A) crack, (B) adhered aluminum, and (C) friction region. 


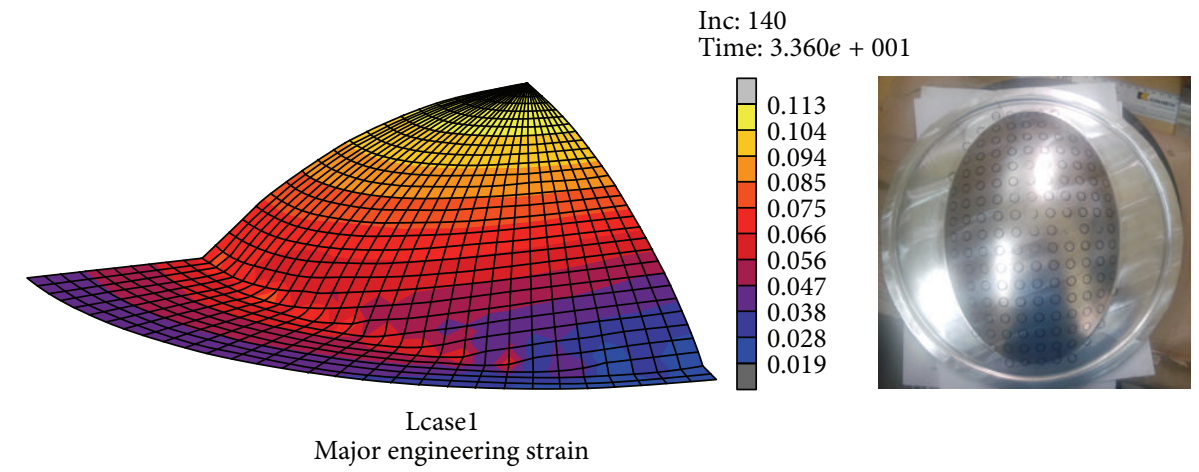

FIGURE 38: Comparison between maximum deformation in MSC-MARC and pratical results for an elliptical nonprocessed sheet.

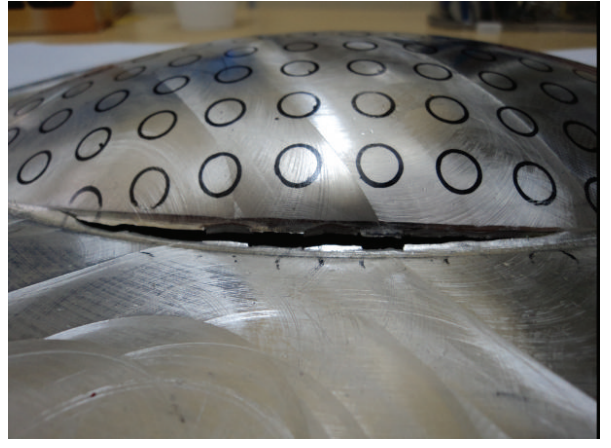

(a)

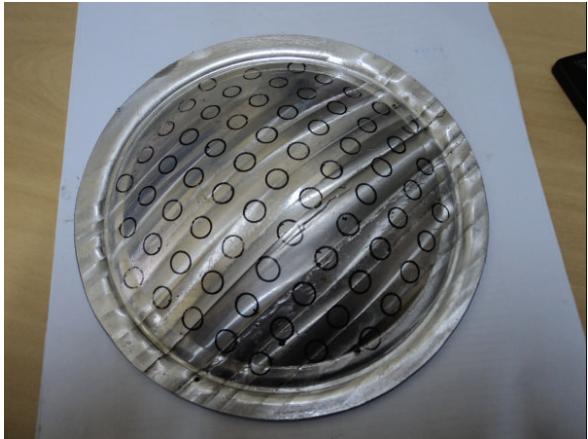

(b)

FIGURE 39: Crack on processed sheets after practical bulge tests. (a) Elliptical sheet and (b) circular sheet.

The formability properties are concluded to be maintained after FSP, which is in agreement with $[13,14]$ in which the aluminum alloys keep the formability properties after the FSP processing. In this case, greater strength is yielded for the FSP material rather than non-FSP material; therefore, better mechanical properties are achieved after FSP.

Comparing Abaqus and MSC-MARC, the stability of the solution in relation to convergence is better for MSCMARC when the contact property is added, while the Abaqus software shows convergence problems. On the other hand, the Abaqus interface is better than that of MSC-MARC. Abaqus also has parametric characteristics, which is an advantage to change the models. The results from the software products were very close, although Abaqus shows different results for the Nakajima studies.

Four tools were constructed and four AA-5083-O sheets were friction stir processed. The wear of the tool was evaluated and no wear was verified after $25150 \mathrm{~mm}$ of processing. A comparison between the FEM bulge test results was established and good approximation was obtained. Sheets with FSP broke before the target pressure was achieved which occurred because of defects in FSP.

\section{Conflict of Interests}

The authors declare that there is no conflict of interests regarding the publication of this paper.

\section{Acknowledgments}

The authors acknowledge the support to the experimental tests carried out at Centro Universitario da FEI, Faculdade de Engenharia Industrial, São Bernardo do Campo, Brazil. They also thank Rudloff Industrial Ltda., São Paulo, Brazil, for the financial support and the manufacture of the tools and specimens and Instituto Mauá de Tecnologia, São Caetano do Sul, Brazil, for the support to the metallographic investigations.

\section{References}

[1] R. L. L. P. Cerveira, Experimental characterization of the mechanical behavior under multiaxial loads of AA2024-T3 sheets welded by friction stir welding (FSW) [M.S. thesis], Graduate Program on Mechanical Engineering, Polytechnic School of Engineering, University of São Paulo, São Paulo, Brazil, 2008, (Portuguese), http://www.teses.usp.br/teses/disponiveis/3/3151/ tde-17112008-161426/pt-br.php .

[2] R. L. L. P. Cerveira and G. F. Batalha, "Multiaxial mechanical strength of AA-2024-T3 aluminium alloy sheets joined by friction stir welding processes," Advanced Materials Research, vol. 83-86, pp. 1243-1250, 2010.

[3] W. M. Thomas, E. D. Nicholas, J. C. Needham, M. G. Murch, P. Temple-Smith, and C. J. Dawes, "Friction Stir Butt Welding, International Patent Appl. n.PCT/GB92/02203 and GB Patent Appl. n. 9125978.8," US Patent n.5,460,317, 1991. 
[4] J. F. Guo, H. C. Chen, C. N. Sun, G. Bi, Z. Sun, and J. Wei, "Friction stir welding of dissimilar materials between AA6061 and AA7075 Al alloys effects of process parameters," Materials and Design, vol. 56, pp. 185-192, 2014.

[5] G. F. Miori, "Mapping the defects on the friction stir processing of AA5083 alloys," Internal Report, Polytechnic School of Engineering, University of São Paulo, São Paulo, Brazil, 2013, (Portuguese).

[6] G. F. Miori, E. F. Prados, and G. F. Batalha, "Investigation of superplasticity in a friction stir processed AA5052 alloy," in Proceedings of the 2nd International Conference on "Friction Stir Welding and Processing" (FSWP '12), pp. 89-91, Saint-Etienne, France, 2012.

[7] R. Pierce, Sheet Metal Forming, The Adam Hilger Series on New Manufacturing Processes and Materials, Adam Hilger, 1991.

[8] R. Caldin, Study of the hydroforming formability of tailored blanks of laser welded steel sheets [Master dissertation], School of Mechanical Engineering, State University of Campinas, Campinas, Brazil, 2006 (Portuguese).

[9] G. Mitukiewicz, K. Anantheshwara, G. Zhou, R. Mishra, and M. Jaina, "A new method of determining forming limit diagram for sheet materials by gas blow forming," Journal of Materials Processing Technology, vol. 214, pp. 2960-2970, 2014.

[10] Z. Marciniak and J. L. Duncan, The Mechanics of Sheet Metal Forming, Edward Arnold, London, UK, 1991.

[11] M. Albakri, F. Abu-Farha, and M. Khraisheh, "A new combined experimental-numerical approach to evaluate formability of rate dependent materials," International Journal of Mechanical Sciences, vol. 66, pp. 55-66, 2013.

[12] W. Lee, K.-H. Chung, D. Kim et al., "Experimental and numerical study on formability of friction stir welded TWB sheets based on hemispherical dome stretch tests," International Journal of Plasticity, vol. 25, no. 9, pp. 1626-1654, 2009.

[13] D. Kim, W. Lee, J. Kim, C. Kim, and K. Chung, "Formability evaluation of friction stir welded 6111-T4 sheet with respect to joining material direction," International Journal of Mechanical Sciences, vol. 52, no. 4, pp. 612-625, 2010.

[14] C. Leitão, B. Emílio, B. M. Chaparro, and D. M. Rodrigues, "Formability of similar and dissimilar friction stir welded AA 5182-H111 and AA 6016-T4 tailored blanks," Materials and Design, vol. 30, no. 8, pp. 3235-3242, 2009.

[15] S. Zimmer, Contribution Al'Industrialisation du Soudage par Friction Malaxage [Ph.D. thesis], l'École Nationale Supérieure d'Arts et Métiers, Paris, France, 2009. 

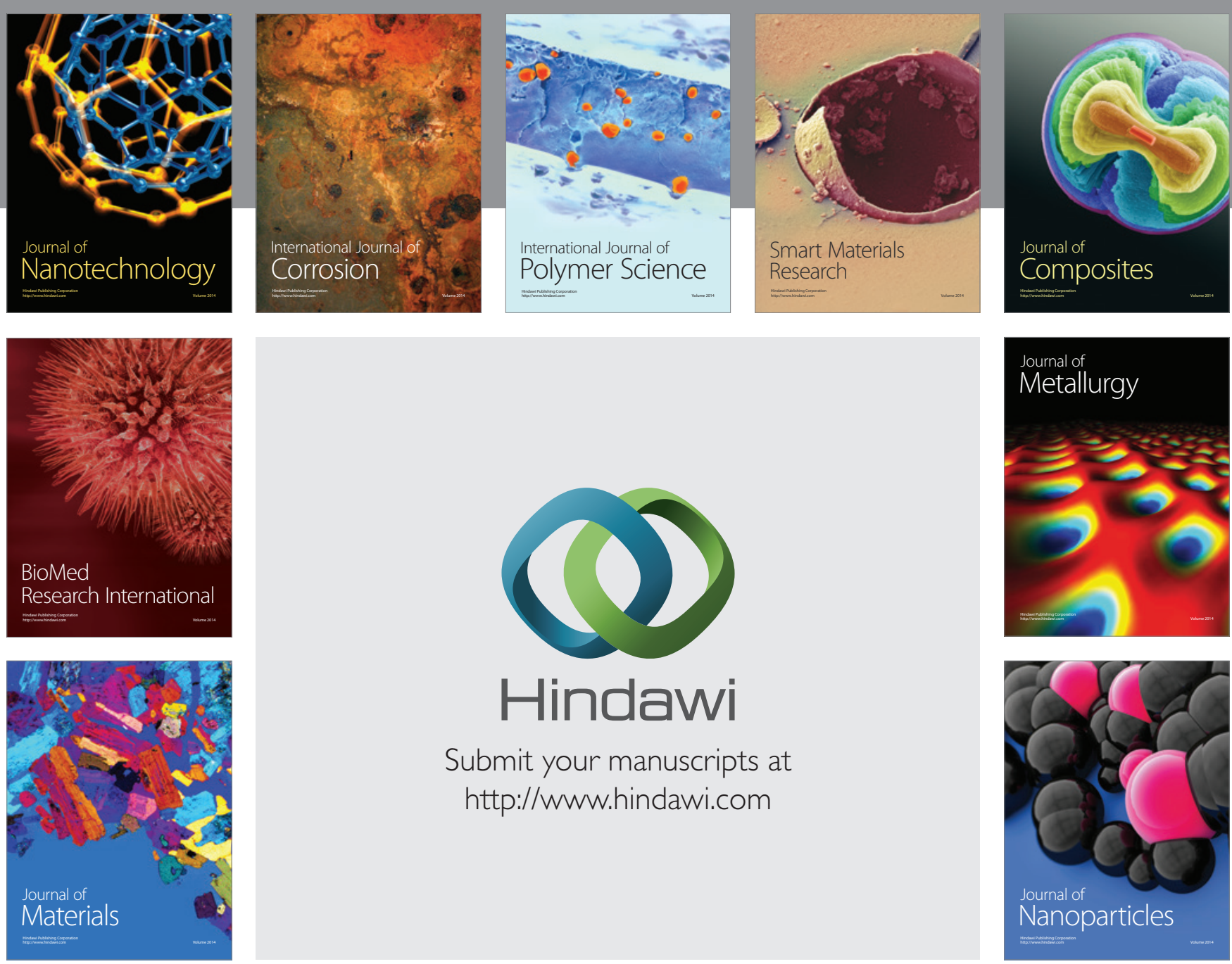

Submit your manuscripts at http://www.hindawi.com
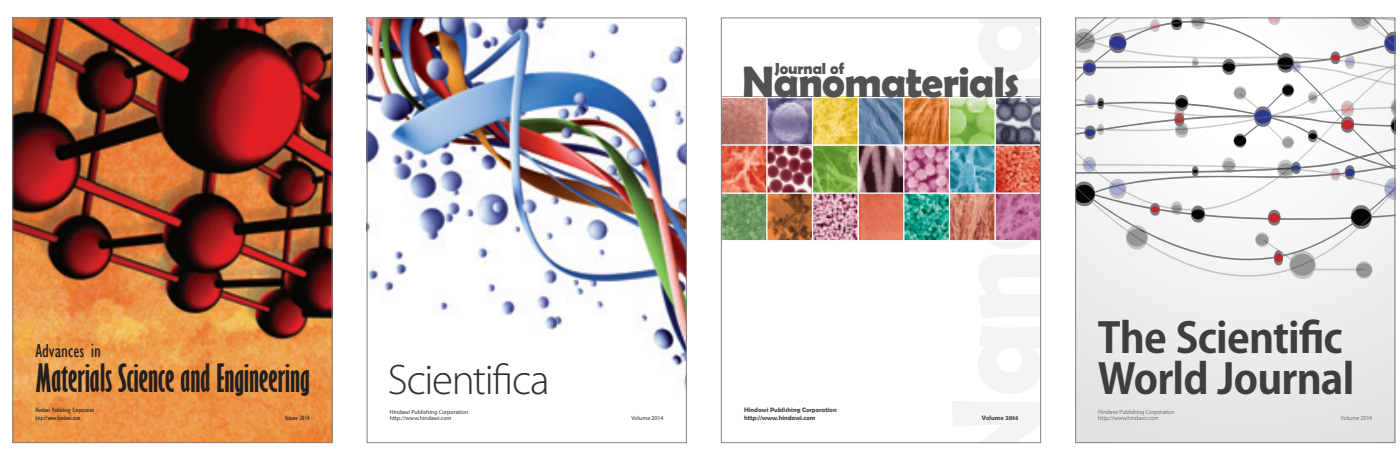

\section{The Scientific World Journal}
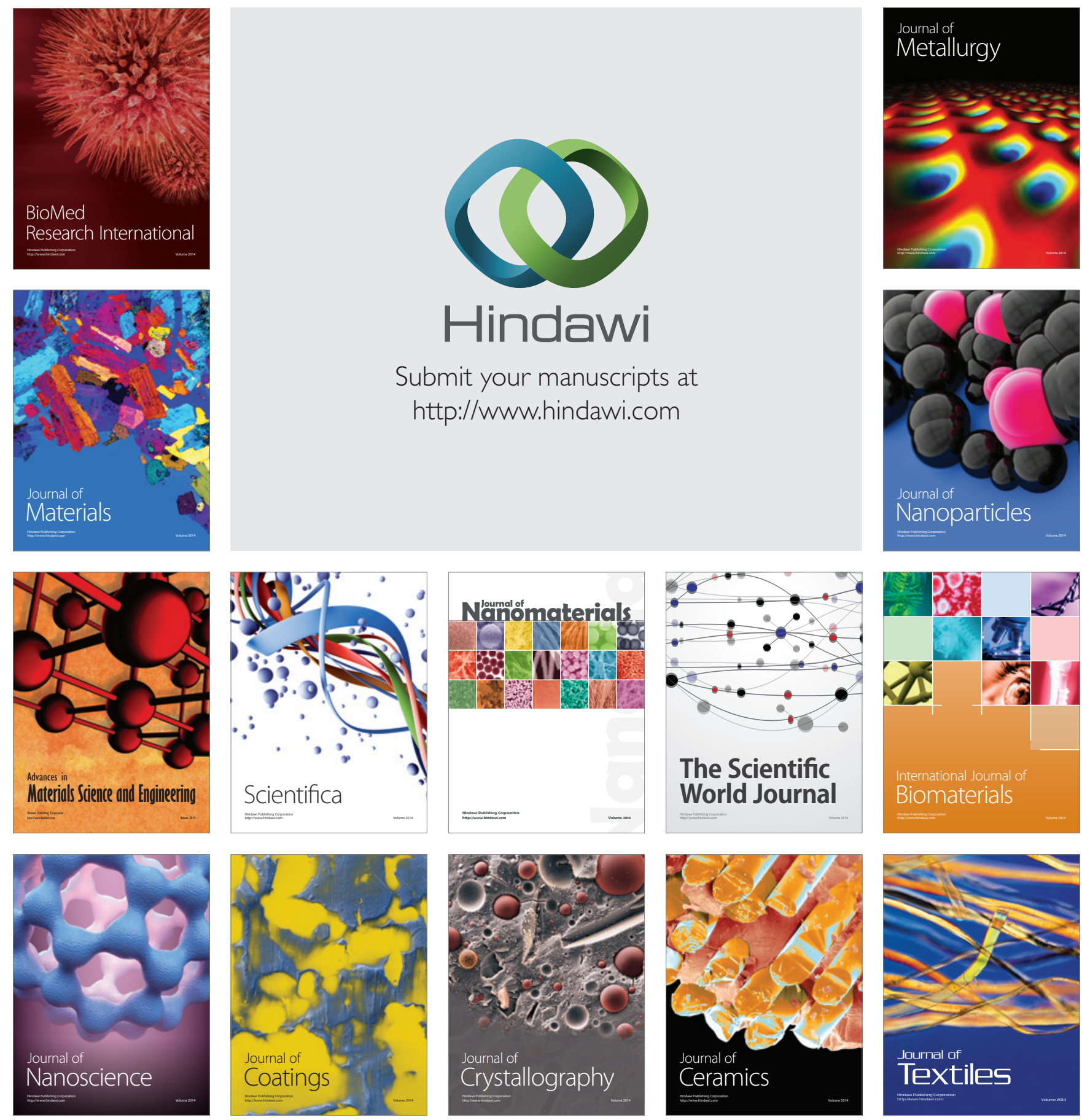